\title{
Buckling Mechanism of Offshore Pipelines: A State of the Art
}

\author{
Debtanu Seth ${ }^{1}\left(\mathbb{D}\right.$, Bappaditya Manna ${ }^{1}$, Jagdish Telangrao Shahu ${ }^{1}$, Tiago Fazeres-Ferradosa ${ }^{2,3, *(\mathbb{D})}$, \\ Francisco Taveira Pinto ${ }^{2,3}$ and Paulo Jorge Rosa-Santos ${ }^{2,3}$ D
}

1 Department of Civil Engineering, Indian Institute of Technology Delhi, Hauz Khas, New Delhi 110016, India; debtanu.seth1995@gmail.com (D.S.); bmanna@civil.iitd.ac.in (B.M.); shahu@civil.iitd.ac.in (J.T.S.)

2 Marine Energy Research Group, CIIMAR - Interdisciplinary Centre of Marine and Environmental Research, 4400-465 Porto, Portugal; fpinto@fe.up.pt (F.T.P.); pjrsantos@fe.up.pt (P.J.R.-S.)

3 Hydraulics, Water Resources and Environmental Division, Department of Civil Engineering, Faculty of Engineering of the University of Porto, 4099-002 Porto, Portugal

* Correspondence: tferradosa@fe.up.pt; Tel.: +351-91-93-89-590

check for updates

Citation: Seth, D.; Manna, B.; Shahu, J.T.; Fazeres-Ferradosa, T.; Pinto, F.T.; Rosa-Santos, P.J. Buckling Mechanism of Offshore Pipelines: A State of the Art. J. Mar. Sci. Eng. 2021, 9, 1074. https://doi.org/10.3390/jmse9101074

Received: 2 September 2021

Accepted: 26 September 2021

Published: 1 October 2021

Publisher's Note: MDPI stays neutral with regard to jurisdictional claims in published maps and institutional affiliations.

Copyright: (c) 2021 by the authors. Licensee MDPI, Basel, Switzerland. This article is an open access article distributed under the terms and conditions of the Creative Commons Attribution (CC BY) license (https:// creativecommons.org/licenses/by/ $4.0 /)$.
Abstract: The buckling analysis of an offshore pipeline refers to the analysis of temperature-induced uplift and lateral buckling of pipelines by analytical, numerical, and experimental means. Thus, the current study discusses different research performed on thermal pipe-buckling and the different factors affecting the pipeline's buckling behaviour. The current study consists of the dependency of the pipe-buckling direction on the seabed features and burial condition; the pre-buckling and post-buckling load-displacement behaviour of the pipeline; the effect of soil weight, burial depth, axial resistance, imperfection amplitude, temperature difference, interface tensile capacity, and diameter-to-thickness ratio on the uplift and lateral resistance; and the failure mechanism of the pipeline. Moreover, the effect of external hydrostatic pressure, bending moment, initial imperfection, sectional rigidity, and diameter-to-thickness ratio of the pipeline on collapse load of the pipeline during buckling were also included in the study. This work highlights the existing knowledge on the topic along with the main findings performed up to recent research. In addition, the reference literature on the topic is given and analysed to contribute to a broad perspective on buckling analysis of offshore pipelines. This work provides a starting point to identify further innovation and development guidelines for professionals and researchers dealing with offshore pipelines, which are key infrastructures for numerous maritime applications.

Keywords: analytical solution; axial resistance; experimental solution; lateral buckling; numerical analysis; pipe bending; pipeline stability; static analysis; state of the art; upheaval buckling

\section{Introduction}

Offshore pipelines are essential infrastructures for a wide variety of maritime structures, namely in oil and gas transport to shore, but also in other types of offshore structures that may include the use of J-tubes and similar buried, exposed or partially buried cables, such as offshore wind turbines and other marine renewable energy infrastructures [1-4]. Therefore, understanding their behaviour in offshore conditions is important for a proper design under oceanic environmental conditions.

For a high-pressure and high-temperature (HP/HT) pipeline, buckling is a widespread phenomenon. Again, it is essential to possess knowledge about the pipe-buckling for designing a stable pipeline. Thus, a rigorous discussion about the causes and effects of pipe-buckling is done here using the available literature. The paper discussed the buckling of the pipelines for different seabed and pipe-burial conditions. The methods to estimate the buckling resistances for surface-laid and buried pipelines using analytical solutions, along with the maximum limit of the resistances, are discussed in this study. The numerical and experimental means to study the effect of parameters such as embedment depth, soil unit weight, pipe diameter, soil friction coefficient, and undrained soil strength on the 
pipe-buckling are also discussed systematically in this study. Moreover, the relationship between the buckling resistance, the most critical influence factor, and axial resistance was also explored. The load subjected to the pipeline during installation and operation was studied, and its role in the pipe collapse under buckling was also studied.

Still, there is need for further exploration of the pipe-buckling during situations such as movement of subsoil or liquefaction of subsoil under earthquake forces or the lateral or vertical movement of pipeline under various hydrodynamic loading [5-7]. The pipe-soil interaction should also be studied in detail for the internal flow [8-10] and the oscillating working platform [11] induced vibration in pipe.

The current paper aims to provide the readers with knowledge of the causes and effects of uplift and lateral buckling of buried or surface-laid pipeline. Furthermore, it also aims to explore the response of the pipeline and the surrounding soil during pipe movement and under different external factors. Thus, the paper contributes to providing a broad overview of the essential knowledge on buckling phenomena of offshore pipelines.

\section{Buckling of Pipeline}

An offshore pipeline transports unprocessed oil and other hydrocarbons from the well to the processing centre at very high temperatures and pressure. Such pipelines are also called 'high pressure-high temperature' (HP/HT) pipelines. Due to this high temperature, the pipeline tends to increase along its length. However, longitudinal compressive stress is induced within the pipeline when the pipeline's longitudinal elongation is restricted by the axial resistance provided by the soil in contact with the pipe. Thus, to release the longitudinal compressive force, the pipeline may buckle. The buckling of the pipelines under different embedment conditions is discussed in this section.

\subsection{Surface-Laid and Partially Embedded Pipeline}

The pipelines are called surface-laid pipelines if they are laid on the seabed during installation. The pipelines laid on the seabed are often subjected to different hydrodynamic forces and embeds within the soil partially. The pipelines are also embedded partially during installation to increase their stability against lateral movement. The forces that act on the pipeline are different external hydrodynamic forces and longitudinal compressive forces. The longitudinal compressive force is generated due to a large temperature difference between the seawater and the fluid transported by the pipe at elevated temperatures. Thus, the longitudinal compressive force further induces buckling in the pipe. The buckling of the pipeline may occur in the vertical or lateral direction.

\subsubsection{Global Upheaval Buckling and Upheaval Buckling Resistance}

The buckling direction of the pipeline mostly depends on the evenness of the seabed. For an even seabed, global lateral buckling is predominant. In contrast, for the uneven or undulated seabed, the chance of global upheaval buckling is very high under the longitudinal compressive force [12-14]. Similarly, a downward global vertical buckling of pipeline can also occur at sunken seabed or when any fault is formed at the subsoil across the pipeline due to soil movement during an earthquake [15]. In Figure 1, the schematic diagrams of the vertical displacement of the pipeline for the above-dictated cases are shown. The flexural behaviour of subsea pipelines with an initial imperfection or in the presence of faults in the subsoil is often studied numerically and analytically considering idealised imperfection shapes $[14,16,17]$. 


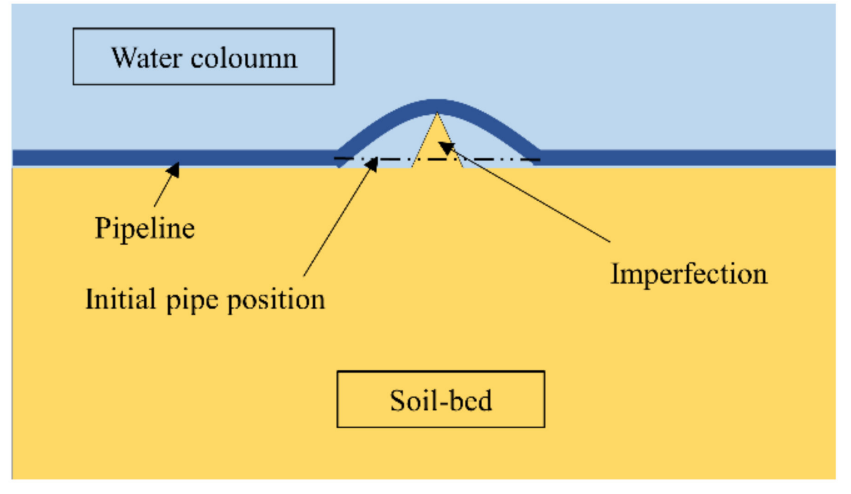

(a)

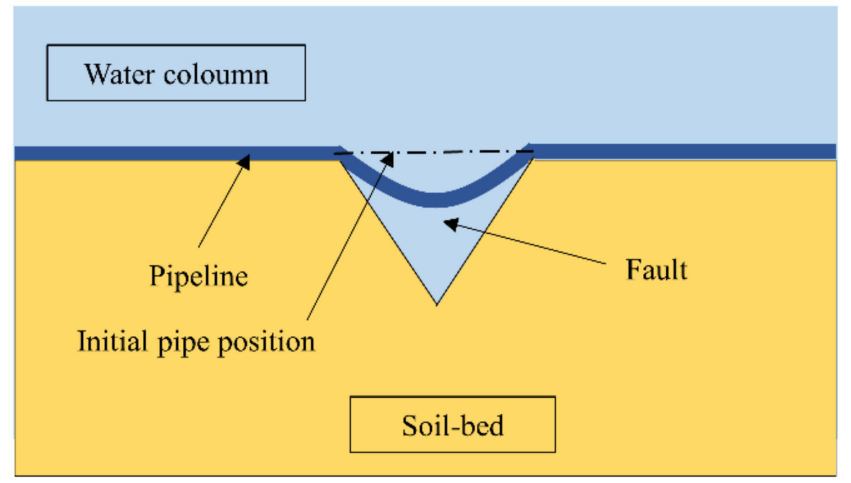

(b)

Figure 1. Vertical displacement of pipeline due to presence of (a) initial imperfection and (b) fault in the seabed.

\section{Analytical Models}

The longitudinal compressive force induced within the pipeline is the major reason behind the buckling of the pipeline. Moreover, the presence of an initial imperfection in the seabed increases the severity of the buckling. So, it was crucial for the designers to estimate the maximum compressive stress induced in the pipeline due to the combined effect of thermal buckling pressure and initial imperfection on the pipeline. Thus, Taylor and Gan [16] performed an analysis on a surface-laid pipeline lying on a fictitious rigid undulated foundation. The maximum compressive stress and bending moment induced on the pipeline due to initial imperfection are obtained from the analysis as follows:

Maximum compressive stress,

$$
\sigma_{m}=\frac{P}{A}+\left|\frac{M_{m} r}{I}\right|
$$

where,

$$
M_{m}=\text { Maximum moment on pipeline }=-0.06938 q\left(L^{2}-L_{0}^{2}\right)
$$

It is to be considered that the above relationship holds good for small deformation studies and needed to be modified for large deformation cases.

A more rigorous study was performed by $\mathrm{Xu}$ and Lin [14]. They studied the initial stress which accumulated within the pipeline while placing them on andulation of seabed under their self-weight. The effect of buckle length, buckle amplitude, and sectional rigidity of the pipeline on the critical global buckling force of the pipeline was also considered. Moreover, three expressions were given empirically to predict the critical axial forces for different undulation's shapes and contact areas. The expressions are given below.

Critical axial force $\left(P_{c r 1}\right)$ for continuous contact between the pipeline and the undulation:

$$
P_{c r_{1}}=0.2974\left(\frac{L^{3} q}{E I}\right)^{0.8351}\left(\frac{H}{L}\right)^{-0.8228}\left(\frac{E I}{L^{2}}\right)
$$

Critical axial force $\left(P_{c r 2}\right)$ for partial contact between the pipeline and the undulation:

$$
P_{c r_{2}}=0.4231\left(\frac{L^{3} q}{E I}\right)^{0.7785}\left(\frac{H}{L}\right)^{-0.7685}\left(\frac{E I}{L^{2}}\right)
$$

Critical axial force $\left(P_{c r 3}\right)$ for point contact between the pipeline and the undulation:

$$
P_{c r_{3}}=1.7471\left(\frac{L^{3} q}{E I}\right)^{0.5989}\left(\frac{H}{L}\right)^{-0.5951}\left(\frac{E I}{L^{2}}\right)
$$


The empirical formula given by $\mathrm{Xu}$ and Lin [14] gives a result within an error range of $\pm 10 \%$ for continuous pipe-seabed contact. While the formulas overestimate the critical capacity factors for pipelines with partial contact with the seabed.

\section{Numerical Models}

Although these analytical studies produced satisfactory results, there was a need for comparing these studies with different 2D or 3D finite element analyses. According to Recommended Practice-DNV RP F110, 2D analysis is sufficient if the pipeline's uplift buckling occurs in a plane. Thus, various researchers have performed both analytical and numerical (FE) analyses and compared the two results [12-14,18-21].

It is observed for a rigid seabed that, for a given initial imperfection amplitude, the safe temperature to trigger global uplift buckling increases with increasing cover depth, soil friction coefficient, and undrained soil strength. Again, the critical temperature (refer to Figure 2) and compressive force (refer to Figure 3) to cause global upheaval buckling decreases with increasing size of initial imperfection $[12-14,18,20]$. The effect of temperature difference on buckling amplitude, maximum axial compression, and axial thermal expansion is more rapid in the post-buckling stage than the pre-buckling stage. It is also found that with the increasing thickness to diameter ratio of the pipeline, the critical buckling force decreased $[13,14,21]$. However, for the soft seabed, the safe temperature and the critical imperfection height for the uplift of pipeline decreases with decreasing soil resistance [19]. Various authors used idealised pipe imperfection shapes for numerical and analytical study of the pipe buckling. However, it is observed from the numerical analysis that, for an initially imperfect pipeline, the critical global buckling temperature is underestimated when the imperfection shape is considered as an idealised shape [13]. The details of the parameters used in the numerical analysis of global upheaval buckling of surface laid pipeline by various authors are given in Table 1 .

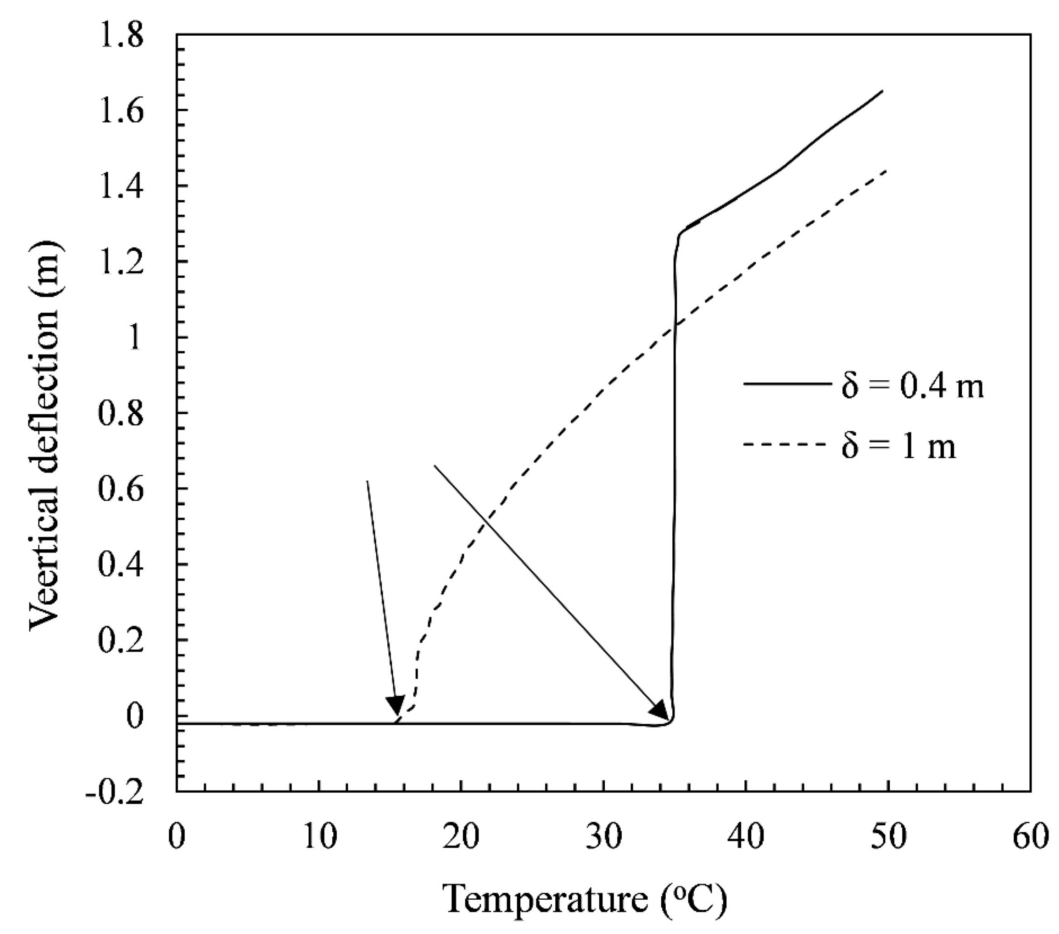

Figure 2. Variation of critical buckling temperature with vertical deflection for different initial imperfection [13]. 


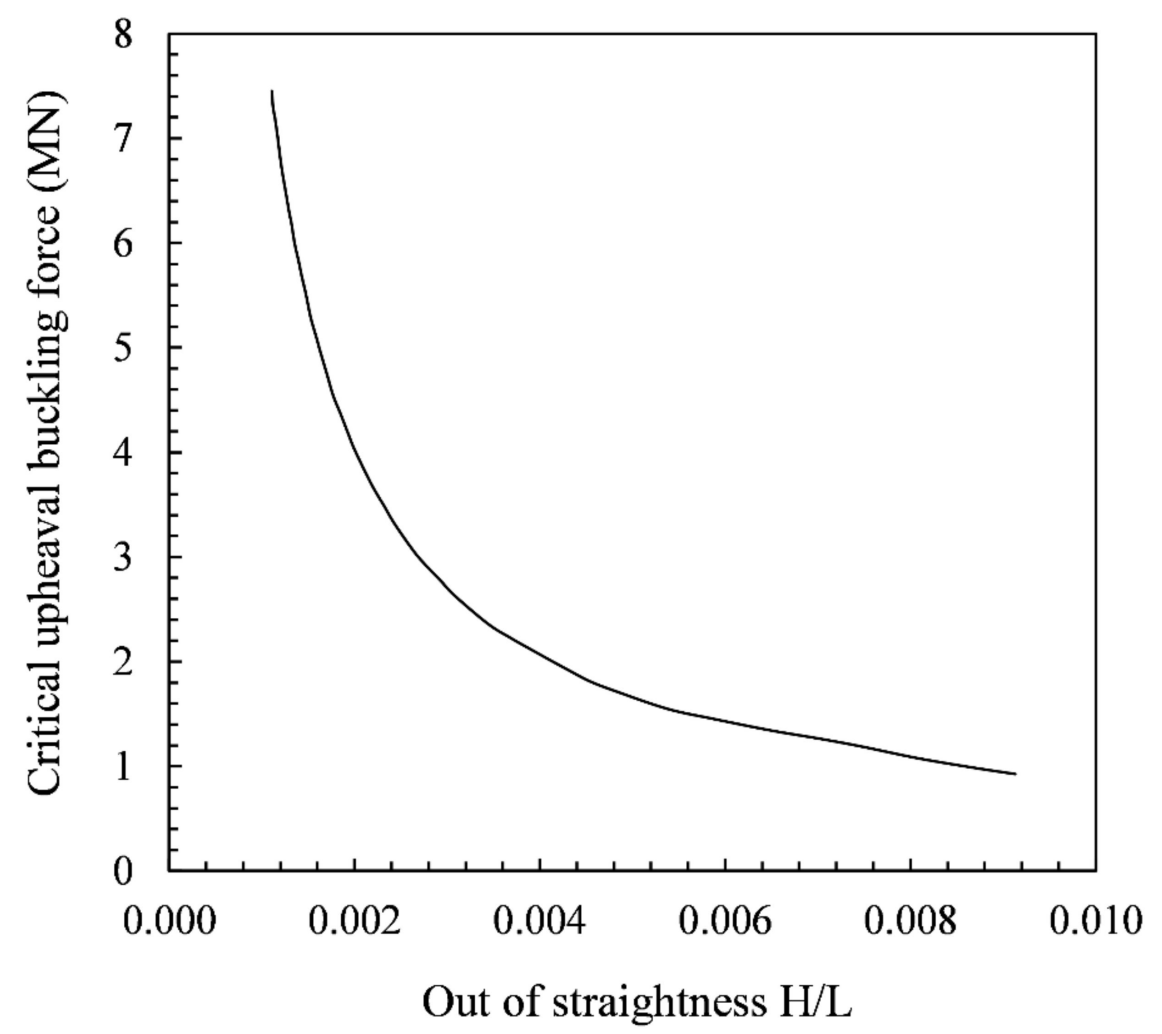

Figure 3. Influence of initial pipe imperfection on critical buckling force [14].

Table 1. Parameter used in the Numerical models for uplift resistance of surface laid pipeline.

\begin{tabular}{|c|c|c|}
\hline Author & Parameter & Magnitude \\
\hline \multirow{6}{*}{ Shi et al. [19] } & Pipe Parameters & \\
\hline & Cross-sectional area of the pipeline $\mathrm{A}\left(\mathrm{cm}^{2}\right)$ & 299.20 \\
\hline & The outer diameter of the pipe, $\mathrm{D}(\mathrm{cm})$ & 65 \\
\hline & The equivalent cross-sectional moment of inertia, $\mathrm{I}\left(\mathrm{cm}^{4}\right)$ & $1.509 \times 10^{5}$ \\
\hline & Modulus of elasticity of pipeline E (GPa) & 206 \\
\hline & Thermal expansion coefficient of Steel, $\alpha\left(1 /{ }^{\circ} \mathrm{C}\right)$ & $1.1 \times 10^{-5}$ \\
\hline \multirow{17}{*}{ Mondal and Dhar [13] } & Pipe Parameters & \\
\hline & Pipe Diameter D (mm) & 219.1 \\
\hline & Pipe wall thickness $\mathrm{t}(\mathrm{mm})$ & 18.3 \\
\hline & Submerged Density of steel, $\rho_{\text {st }}{ }^{\prime}\left(\mathrm{kg} / \mathrm{m}^{3}\right)$ (Steel) & 6850 \\
\hline & Modulus of Elasticity of Steel, E (MPa) & $20.7 \times 10^{4}$ \\
\hline & Poisson's ratio of Steel, $v$ & 0.30 \\
\hline & Specified Minimum Yield strength of Steel, $\sigma_{\mathrm{y}}(\mathrm{MPa})$ & 450 \\
\hline & Specified Minimum Tensile Strength of Steel, $\sigma_{\mathrm{u}}(\mathrm{MPa})$ & 535 \\
\hline & Total strain at ultimate strength of Steel, $\varepsilon_{u}$ & 0.043 \\
\hline & Thermal expansion coefficient of Steel, $\alpha(\mathrm{m} / \mathrm{m} / \circ \mathrm{C})$ & $1.17 \times 10^{-5}$ \\
\hline & Soil Parameters & \\
\hline & Coefficient of friction & 0.40 \\
\hline & Submerged Density, $\rho_{\mathrm{s}}{ }^{\prime}\left(\mathrm{kg} / \mathrm{m}^{3}\right)$ & 600 \\
\hline & Modulus of Elasticity, E (MPa) & 40 \\
\hline & Poisson's Ratio, $v$ & 0.25 \\
\hline & Friction angle $\left({ }^{\circ}\right)$ & 42 \\
\hline & Dilation angle $\left(^{\circ}\right)$ & 15 \\
\hline
\end{tabular}


Table 1. Cont.

\begin{tabular}{|c|c|c|}
\hline Author & Parameter & Magnitude \\
\hline \multirow{13}{*}{$\mathrm{Xu}$ and Lin [14] } & Pipe Parameters & \\
\hline & The outer diameter of the steel pipe, D (mm) & 385 \\
\hline & The thickness of the steel pipe wall, $\mathrm{t}(\mathrm{mm})$ & 12.0 \\
\hline & The Young's modulus, E (GPa) & 207 \\
\hline & The Poisson's ratio, $v$ & 0.3 \\
\hline & The equivalent cross-sectional moment of inertia, $\mathrm{I}\left(\mathrm{m}^{4}\right)$ & $2.22 \times 10^{-4}$ \\
\hline & The equivalent cross-sectional area, $\mathrm{A}\left(\mathrm{m}^{2}\right)$ & 0.0136 \\
\hline & The density of pipe steel, $\rho_{\mathrm{p}^{\prime}}\left(\mathrm{kg} / \mathrm{m}^{3}\right)$ & 7800 \\
\hline & The density of the outer concrete coating, $\rho_{\mathrm{c}}\left(\mathrm{kg} / \mathrm{m}^{3}\right)$ & 3044 \\
\hline & The density of seawater $\left(\mathrm{kg} / \mathrm{m}^{3}\right)$ & 1025 \\
\hline & The density of internal flow, $\rho\left(\mathrm{kg} / \mathrm{m}^{3}\right)$ & 800.0 \\
\hline & The distributed load (submerged weight) per unit length, $\mathrm{q}(\mathrm{N} / \mathrm{m})$ & 699.3 \\
\hline & The thermal expansion coefficient, $\alpha_{\mathrm{s}}\left(/{ }^{\circ} \mathrm{C}\right)$ & $1.17 \times 10^{-5}$ \\
\hline \multirow{19}{*}{ Liang et al. [15] } & Pipe Parameters & \\
\hline & External diameter D (m) & 0.2731 \\
\hline & Wall thickness $\mathrm{t}(\mathrm{m})$ & 0.0206 \\
\hline & Steel density $\rho_{\mathrm{p}}{ }^{\prime}\left(\mathrm{kg} / \mathrm{m}^{3}\right)$ & 7850 \\
\hline & Young's modulus E (GPa) & 206 \\
\hline & Poisson ratio of steel, $v_{p}$ & 0.3 \\
\hline & Yield stress of steel $\sigma_{\mathrm{y}}(\mathrm{MPa})$ & 448 \\
\hline & Thermal coefficient $\alpha\left({ }^{\circ} \mathrm{C}^{-1}\right)$ & $11 \times 10^{-6}$ \\
\hline & Initial temperature $\mathrm{T}_{\mathrm{i}}\left({ }^{\circ} \mathrm{C}\right)$ & 5 \\
\hline & Product temperature $\mathrm{T}_{\text {if }}\left({ }^{\circ} \mathrm{C}\right)$ & 90 \\
\hline & Internal pressure $\mathrm{p}_{\mathrm{i}}(\mathrm{MPa})$ & 20 \\
\hline & Soil Parameters & \\
\hline & Cohesion of soil C (kPa) & 18 \\
\hline & Internal friction angle $\varphi\left(^{\circ}\right)$ & 18.6 \\
\hline & Young's modulus of soil $\mathrm{E}_{\mathrm{S}}(\mathrm{MPa})$ & 5 \\
\hline & Poisson ratio of soil $v_{\mathrm{s}}$ & 0.2 \\
\hline & Density of soil $\rho_{\mathrm{s}}^{\prime}\left(\mathrm{kg} / \mathrm{m}^{3}\right)$ & 1923 \\
\hline & Shear strength of soil, $\mathrm{S}_{\mathrm{u}}(\mathrm{kPa})$ & 6 \\
\hline & Friction coefficient, $\mu$ & 0.5 \\
\hline \multirow{13}{*}{ Chen et al. [21] } & Pipe Parameters & \\
\hline & External diameter D (mm) & 323.9 \\
\hline & Wall thickness of pipeline $\mathrm{t}(\mathrm{mm})$ & 12.7 \\
\hline & Elastic modulus of steel $E_{p}(\mathrm{GPa})$ & 206 \\
\hline & Steel density $\rho_{\mathrm{p}}\left(\mathrm{kg} / \mathrm{m}^{3}\right)$ & 7850 \\
\hline & Coefficient of thermal expansion $\alpha\left(/{ }^{\circ} \mathrm{C}\right)$ & $1.1 \times 10^{-5}$ \\
\hline & Soil Parameters & \\
\hline & Axial friction coefficient $\mu_{\mathrm{a}}$ & 0.5 \\
\hline & Submerged Soil Density $\rho_{\mathrm{s}}{ }^{\prime}\left(\mathrm{kg} / \mathrm{m}^{3}\right)$ & 780 \\
\hline & Cohesion of Soil C $(\mathrm{kPa})$ & 18 \\
\hline & Elastic modulus of Soil $\mathrm{E}_{\mathrm{S}}(\mathrm{MPa})$ & 3.26 \\
\hline & Internal friction angle of soil $\varphi\left({ }^{\circ}\right)$ & 18.6 \\
\hline & Shear strength of soil $\mathrm{s}_{\mathrm{u}}(\mathrm{kPa})$ & 3.26 \\
\hline
\end{tabular}

\subsubsection{Global Lateral Buckling and Lateral Buckling Resistance}

The pipe-soil frictional resistance provides the pipeline's resistance against the lateral movement for an on-bottom subsea pipeline lying on an even seabed. Thus, the magnitude of the lateral frictional resistance is the vertical load coming on the pipeline, multiplied by the coefficient of friction (usually lesser than 1 ) between pipe and soil. While, for the 
uplifting of the pipeline, the pipe has to overcome the whole vertical load coming on the pipeline. Thus, the possibility of the global lateral buckling is far greater than the possibility of global upheaval buckling for a pipeline laid on an even seabed. The phenomenon of global lateral buckling or snaking of a surface-laid pipeline is schematically shown in Figure 4 .

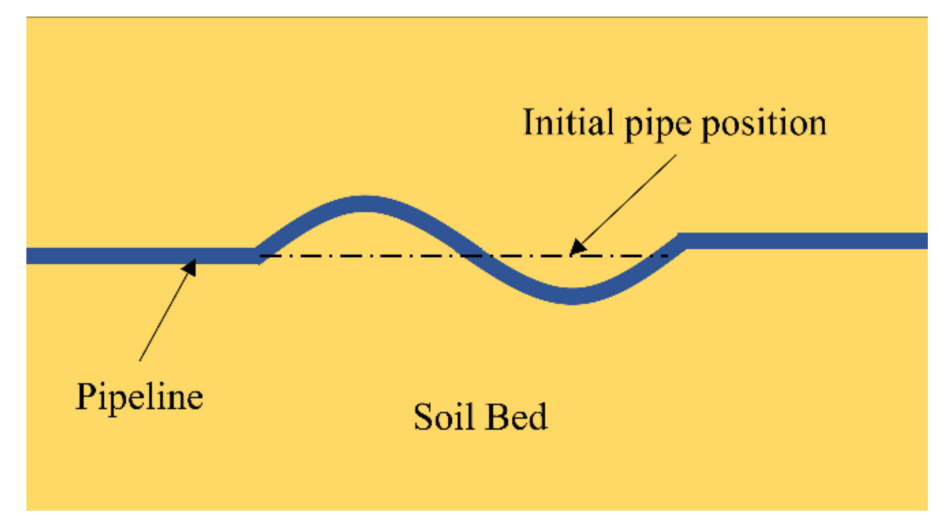

Figure 4. Global lateral buckling or snaking of a surface-laid pipeline.

Analytical Models

Several researchers used analytical methods to deduce the relationship between the global buckling resistances and different influence factors, theoretically or empirically. Initially, the analytical models were limited to the calculation of pipeline behaviour under vertical and horizontal loadings only. The pipe surface was considered rectangular because there was no significant difference in vertical bearing capacity for rectangular and circular pipelines [22]. Thus, Hansen [23] analysed an inclined, loaded pipeline to determine the vertical and lateral load coming on the pipeline. The limiting horizontal load was given as:

$$
V_{H}=C\left(B+6 w_{d}\right)
$$

However, gradually the researchers upgraded the analytical approaches to explore the interaction between pipe and soil for the laterally loaded pipelines [24-26]. Unlike the classical models, the model proposed by Schotman and Stork [24] claimed to calculate loads per unit length of the pipeline, not only for vertical and horizontal displacement but for any given displacement path. The model was also considered to calculate the displacement of a pipeline when the load path is given. The relation between load on the pipeline and displacement of the pipe was given as:

$$
\Delta F_{H}=\left[D_{e}-\alpha_{d} \frac{D_{e} \frac{\delta g_{p}}{\delta F_{H}} \frac{\delta f}{\delta F_{H}}{ }^{T} D_{e}}{h+{\frac{\delta f}{\delta F_{H}}}^{T} D{\frac{\delta g_{p}}{\delta F_{H}}}^{-}}\right] \Delta u
$$

The results predicted from the analytical formula was observed to agree well with the numerical analysis results. However, the proposed model still needed to be compared with experimental models. Moreover, the proposed model poorly agrees with the numerical analysis result below the elastic limit, but this disagreement becomes insignificant for large displacement analysis.

Again, the breakout resistance of a laterally loaded pipe was given as [25];

$$
\frac{F_{b r k}}{F_{C}}=\mu+\frac{F_{R}}{F_{C}}
$$

where,

$$
\frac{F_{R}}{F_{C}}=\left(a_{1} k_{s}-b_{1} k_{s}^{2}\right)\left(\frac{w}{D}\right)^{1.25} \quad \text { if, } \mathrm{k}_{\mathrm{s}}<26.7
$$




$$
\begin{gathered}
\frac{F_{R}}{F_{C}}=k_{s}\left(\frac{w}{D}\right)^{1.25} \quad \text { if, } \mathrm{k}_{\mathrm{s}}>26.7 \\
k_{s}=\frac{\gamma_{s} / D^{2}}{W_{P}-F_{Z}}=\frac{\gamma_{s} / D^{2}}{F_{C}} \\
F_{C}=W_{P}-F_{Z}
\end{gathered}
$$

The above formulation holds good for $\mathrm{w} \leq 0.25 \mathrm{D}$. While for higher $\mathrm{w}$, the model starts deviating from the actual values. To provide a model which holds useful even beyond $w>0.25 \mathrm{D}$, another researcher [27] modified the constant ' $b$ '. They considered the value of ' $b$ ' within $0.15-1$. Thus, the modified model is observed to predict the results with a lesser than $10 \%$ deviation. The force parameters mentioned in the Equations (6)-(18) are shown using a schematic diagram in Figure 5.

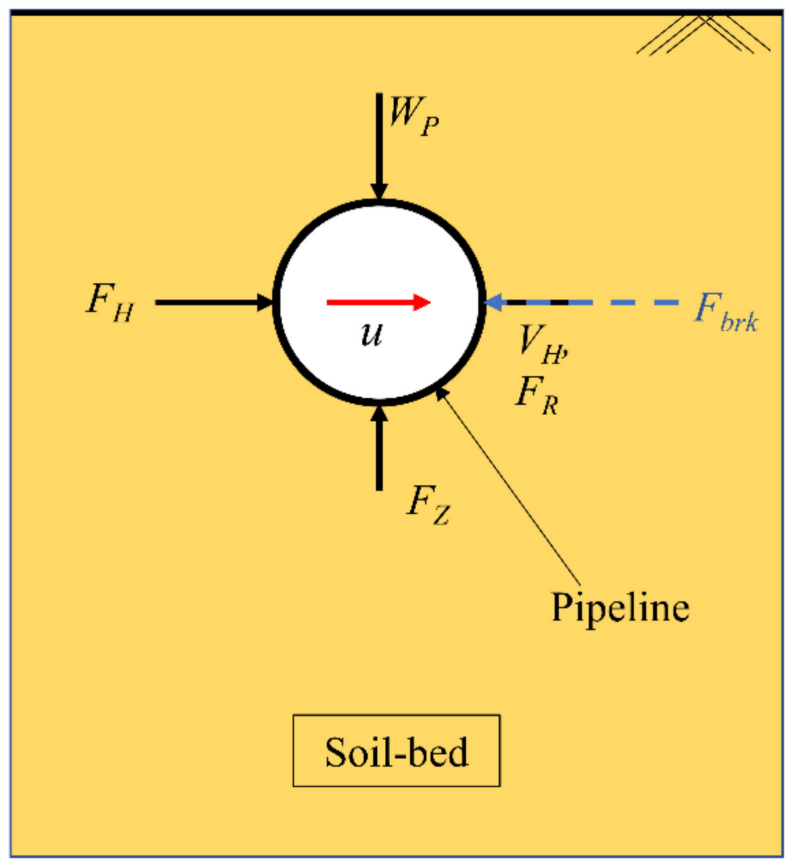

Figure 5. A schematic diagram showing the direction and location of the forces used in the Equations (6)-(18).

Similarly, the effect of pipe weight on the lateral resistance was studied [26] and a formula was proposed to predict the lateral resistance, as follows.

$$
\frac{V_{H}}{V_{u \max }}=\left(\frac{V_{H \max }}{V_{u \max }}\right) \beta\left(\frac{V_{u}}{V_{u \max }}\right)^{\beta_{1}}\left(1-\frac{V_{u}}{V_{u \max }}\right)^{\beta_{2}}
$$

where,

$$
\beta=\frac{\left(\beta_{1}+\beta_{2}\right)^{\beta_{1}+\beta_{2}}}{\beta_{1} \beta_{1} \beta_{2} \beta_{2}}
$$

However, in the further analysis [28], the above relations are slightly modified as follows:

$$
\begin{gathered}
\beta_{1}=0.089\left(0.66-\frac{w}{D}\right) \\
\beta_{2}=0.087\left(0.64-\frac{w}{D}\right) \\
\frac{V_{H}}{V_{u \max }}=0.31\left(0.55+\frac{w}{D}\right) .
\end{gathered}
$$


The proposed model produced a higher peak normalised lateral resistance $\left(\frac{V_{H, \max }}{s_{U} D}\right)$ value compared to the model proposed by previous authors $[26,29]$. The discrepancy in the peak lateral resistance was attributed to the difference in pipe installation procedure. The comparison of the predicted result obtained from Equations (13) and (14) with the numerically obtained (ABAQUS) result is shown in Figure 6.

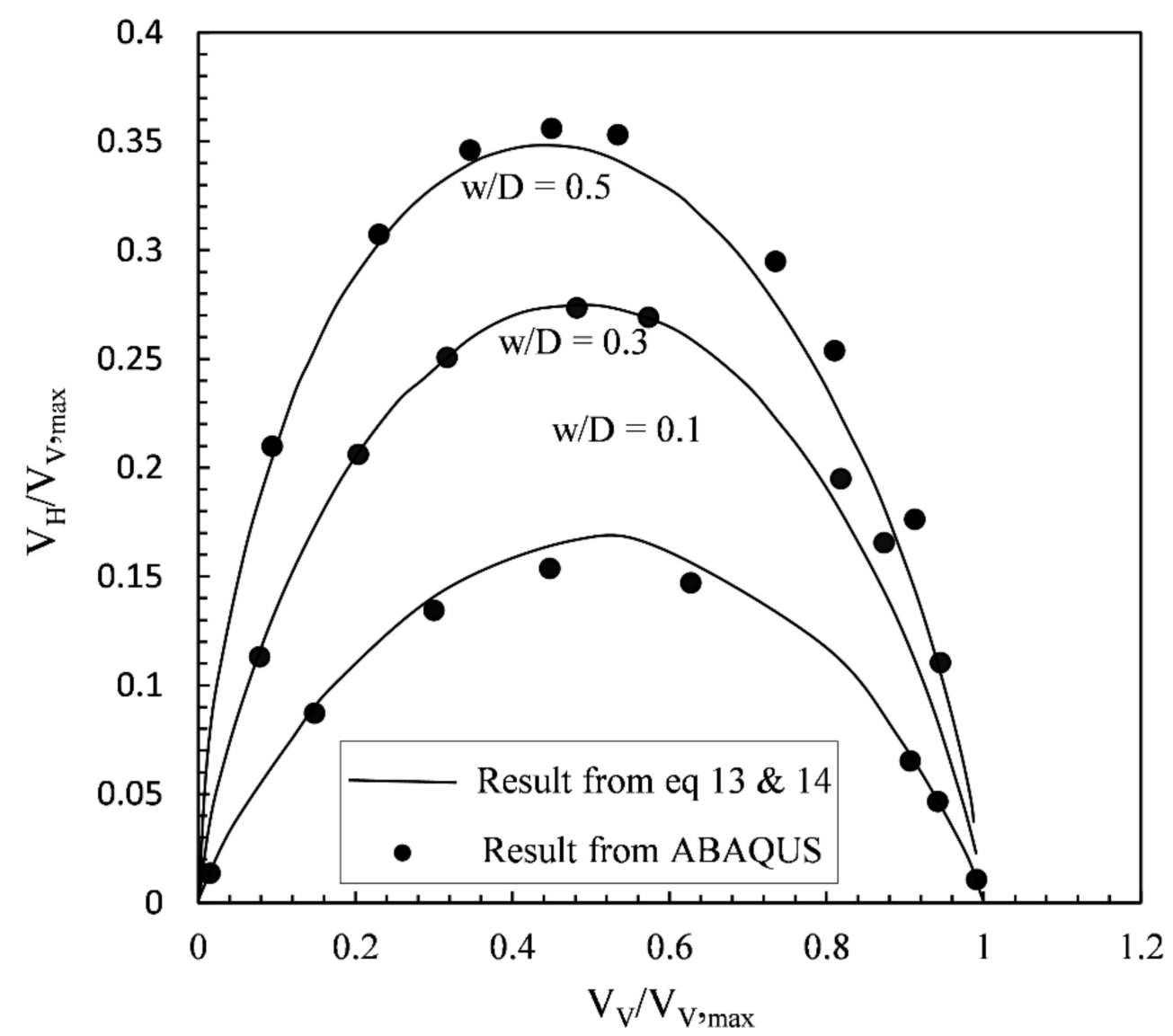

Figure 6. Comparison of predicted results from Equations (13) and (14) with results obtained from FE Analysis [26].

On the other hand, White and Cheuk [30] extended a small-displacement model to obtain a surface-laid pipeline lateral response for large displacement under cyclic loading. The authors also considered the formation of berm during large displacement of a pipeline. Thus, the berm resistance was given as,

$$
V_{H b e r m}=\left(\frac{V_{H b e r m}}{D s_{U}}\right)=\left(a_{2} \lambda v^{b_{2}} \times \frac{u}{D}\right)^{\delta}
$$

Here,

$$
\frac{t_{\text {plough }}}{D}=a_{2} v^{b_{2}}=a_{2}\left(\frac{V_{u}}{D s_{U}}\right) b_{2}
$$

In this study, the authors studied the berm formation during large displacement of a pipeline under lateral loading. It is observed that the lateral resistance further increased with increasing berm formation.

One author [31] used energy method to deduce an analytical solution to investigate the global buckling modes of an offshore pipeline and also to explore the relationship between critical buckling temperature, buckling amplitude, and buckling length. They considered two high-order idealised buckling modes of a pipeline, as shown in Figure 7a,b, for analytical deduction of the expressions given in Equations (19) and (20), respectively. 


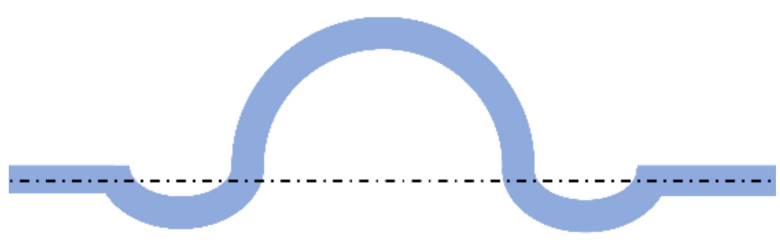

(a)

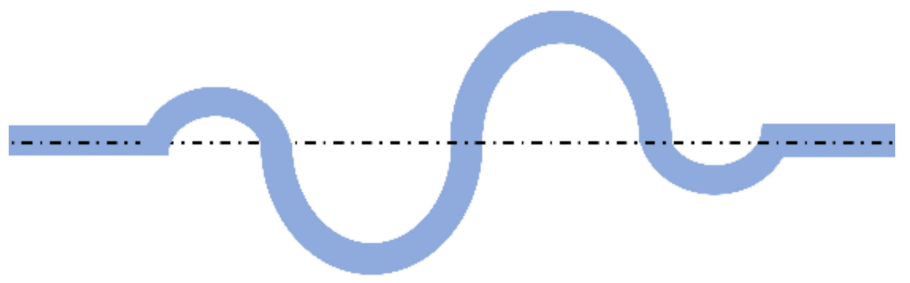

(b)

Figure 7. Idealised shapes (a). Shape 1 and (b) Shape 2, used in the analytical study [31].

For shape 1, the relation between buckling temperature and buckling length:

$$
E_{p} A \alpha \Delta T=33.99 \frac{E I}{L^{2}}+1.298 f_{1} L\left(\sqrt{1+1.69 \times 10^{-4} m^{2} L^{5}\left(\frac{E A}{f_{1}}\right)}-1\right)
$$

the relation between buckling temperature and buckling amplitude:

$$
E_{p} A \alpha \Delta T=3.46\left(\frac{f_{1} E I}{H_{m}}\right)^{0.5}+4.06 f_{1}\left(\frac{H_{m}}{m}\right)^{0.25}\left(\sqrt{1+0.051 m v_{m}\left(\frac{H_{m}}{m}\right)^{0.25}\left(\frac{E A}{f_{1}}\right)}-1\right)
$$

For shape 2, the relation between buckling temperature and buckling length:

$$
E_{p} A \alpha \Delta T=28.19 \frac{E I}{L^{2}}+1.61 f_{1} L\left(\sqrt{1+2.14 \times 10^{-4} m^{2} L^{5}\left(\frac{E A}{f_{1}}\right)}-1\right)
$$

the relation between buckling temperature and buckling amplitude:

$$
E_{p} A \alpha \Delta T=2.94\left(\frac{f_{1} E I}{H}\right)^{0.5}+3.09 f_{1}\left(\frac{H}{m}\right)^{0.25}\left(\sqrt{1+0.06 m H\left(\frac{H}{m}\right)^{0.25}\left(\frac{E A}{f_{1}}\right)}-1\right)
$$

The above expressions only produce good results if the actual buckling assumes the shape of the above idealised shapes. Moreover, several researchers also observed that the models deduced using idealised global buckling shapes underestimates the results, compared to the results obtained from the analysis performed using actual buckling shapes [13].

\section{Numerical Models}

Several researchers used analytical methods to deduce the relationship between the global buckling resistances and different influence factors, theoretically or empirically. Initially, the analytical models were limited to the calculation of pipeline behaviour under vertical and horizontal loadings only. The pipe surface was considered

Again, the buckling amplitude and length were observed to be increasing non-linearly with increasing diameter-to-thickness ratio and temperature. The pipe-buckling was also observed to decrease with increasing soil frictional resistance, and for very high soilfrictional resistance, the reduction in pipe-buckling is significant. Again, from Figure 8, it can be observed that, with increasing displacement, the lateral resistance initially increased and later achieved a steady-state condition. Furthermore, the lateral resistance of pipeline increased with increasing pipe weight and depth of embedment and decreased with increasing diameter-to-thickness ratio of pipeline [27,28,31,32]. Zhu et al. [32] introduced a term called critical length $\left(L_{c r}\right)$. Critical length $\left(L_{c r}\right)$ was defined as the length above which the increase in pipeline length does not affect the local buckling. This critical length $\left(L_{c r}\right)$ 
is considered to have a significant effect on the local buckling of a pipeline. The $L_{c r}$ of a pipeline was observed to be increased with the increasing diameter of the pipeline.

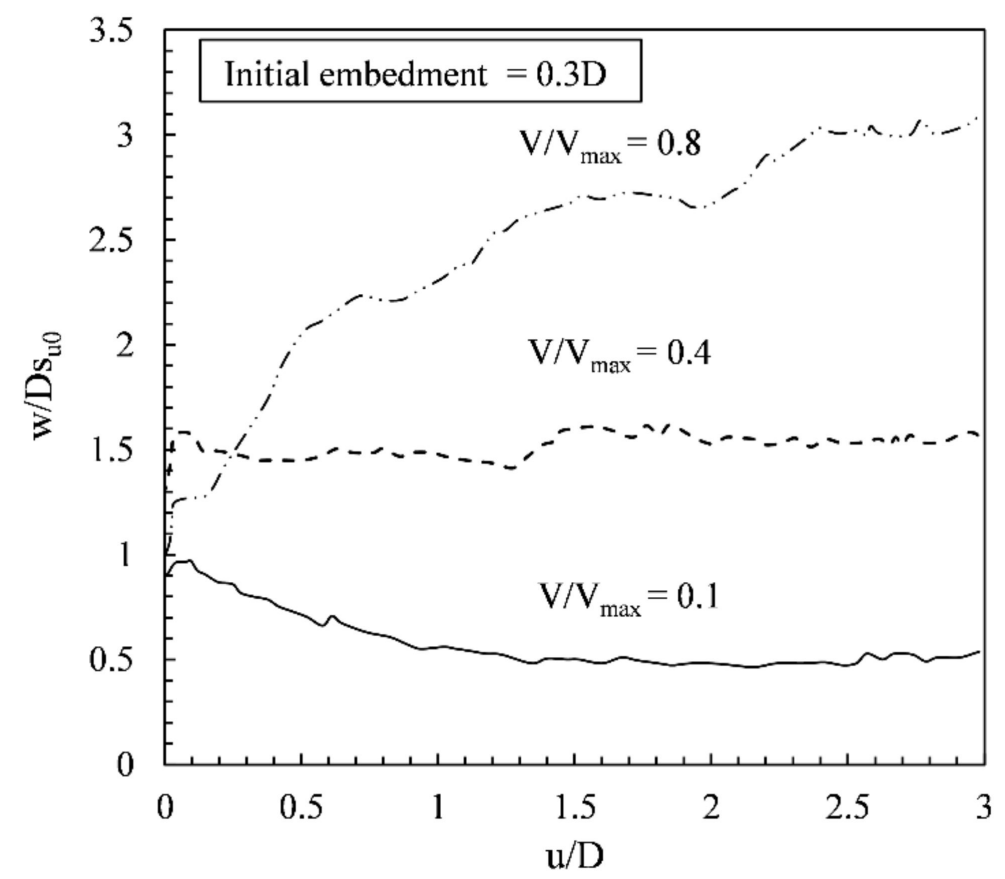

Figure 8. Variation of normalised lateral resistance of a partially buried pipeline with pipe displacement and pipe weight [28].

Several authors have taken into account the phenomenon of berm formation and performed large deformation finite element analysis of the pipe buckling $[27,28,33-38]$. Typical behaviour of horizontal resistance with the variation of horizontal pipe displacement and the effect of berm formation and pipe weight on the horizontal resistance of the pipeline is shown in Figure 9. Thus, it can be observed from Figure 9 that the lateral resistance increased with increasing soil displacement up to a peak value. At post peak condition, the lateral resistance immediately achieves a steady state for a heavy pipe. While for a light pipe, the lateral resistance decreases immediately after peak and then reaches the steady-state. The above phenomenon is attributed to the formation of berm during large amplitude lateral displacement of a pipeline.

The details of the parameters used in the numerical analysis of lateral buckling of surface laid pipeline by various authors are given in Table 2 .

\section{Experimental Models}

The different aspects of global lateral buckling and the factors affecting global lateral buckling are explored experimentally by various researchers. It was observed from centrifugal model tests on pipeline segments that the horizontal resistance was increased with increasing lateral displacement up to a peak value for a surface-laid pipeline [39]. For Partially embedded pipelines, the lateral resistance is also observed to be increasing with increasing embedment depth [39-41].

A new methodology to monitor the lateral displacement using distributed fibre optic technique was also explored by different researchers [42-46]. The authors used the Brillouin optical time-domain analysis (BOTDA) system to measure the pipeline's longitudinal strain and lateral displacements. It was observed that the pipelines were subjected to bending even under very small axial compression force when initial imperfection was there. Moreover, the lateral displacement was observed to be increasing with increasing axial compressive force. It is also observed that a buckling lobe is formed for lower load cases due to initial imperfection, which disappeared for higher compressive loads [46]. 


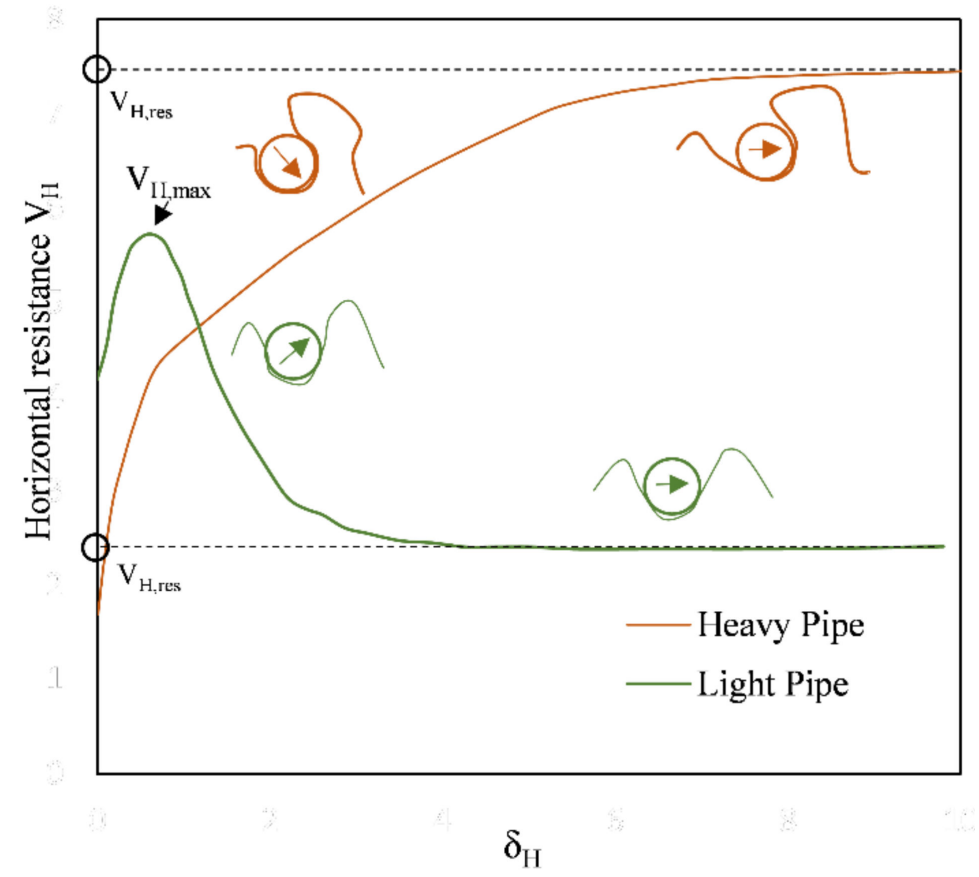

Figure 9. Pipe response during the lateral motion for pipelines with different weights [28].

Table 2. Parameter used in the Numerical models for lateral resistance of surface laid pipeline.

\begin{tabular}{|c|c|c|}
\hline Author & Parameter & Magnitude \\
\hline \multirow{25}{*}{ Liu et al. [31] } & Pipe Parameters & \\
\hline & External diameter D (mm) & 273.1 \\
\hline & Wall thickness $\mathrm{t}(\mathrm{mm})$ & 20.6 \\
\hline & Elastic modulus of pipe material, $\mathrm{E}_{\mathrm{p}}(\mathrm{GPa})$ & 207 \\
\hline & Unit weight of Steel $\gamma_{\mathrm{p}}\left(\mathrm{kN} \cdot \mathrm{m}^{-3}\right)$ & 76.9 \\
\hline & Submerged self-weight per unit length of the pipeline $W_{P}\left(\mathrm{kN} \cdot \mathrm{m}^{-1}\right)$ & 0.75 \\
\hline & Yield stress of steel $\sigma_{\mathrm{y}}(\mathrm{MPa})$ & 448 \\
\hline & Coefficient of thermal expansion for Steel $\alpha\left({ }^{\circ} \mathrm{C}^{-1}\right)$ & 0.000011 \\
\hline & Poisson ratio of soil $\alpha_{\mathrm{s}}$ & 0.3 \\
\hline & Density of water $\rho_{\mathrm{w}}\left(\mathrm{kg} \cdot \mathrm{m}^{-3}\right)$ & 1026.4 \\
\hline & Density of contents $\rho_{\text {if }}\left(\mathrm{kg} \cdot \mathrm{m}^{-3}\right)$ & 486.136 \\
\hline & Internal pressure $\mathrm{p}_{\mathrm{i}}(\mathrm{MPa})$ & 13.8 \\
\hline & Ambient temperature $\mathrm{T}_{\mathrm{S}}\left({ }^{\circ} \mathrm{C}\right)$ & 16 \\
\hline & Product temperature $\mathrm{T}_{\text {if }}\left({ }^{\circ} \mathrm{C}\right)$ & 104 \\
\hline & Water depth $Z_{\mathrm{W}}(\mathrm{m})$ & 108 \\
\hline & Lateral friction $\mu$ & 0.5 \\
\hline & Soil Parameters & \\
\hline & Layer 1 & Silty clay \\
\hline & Thickness of soil layer $1 \Delta \mathrm{z}(\mathrm{m})$ & 2.3 \\
\hline & Effective unit weight of soil $\gamma_{\mathrm{s}}\left(\mathrm{kN} \cdot \mathrm{m}^{-3}\right)$ & 9 \\
\hline & Undrained shear strength $\mathrm{s}_{\mathrm{u}}(\mathrm{kPa})$ & 4 \\
\hline & Layer 2 & Silty fine sand \\
\hline & Thickness of soil layer $2 \Delta z(m)$ & 8.1 \\
\hline & Effective unit weight of soil $\gamma_{\mathrm{s}}\left(\mathrm{kN} \cdot \mathrm{m}^{-3}\right)$ & 9.6 \\
\hline & Friction angle $\phi\left(^{\circ}\right)$ & 25 \\
\hline
\end{tabular}


Table 2. Cont.

\begin{tabular}{|c|c|c|}
\hline Author & Parameter & Magnitude \\
\hline \multirow{13}{*}{ Chatterjee et al. [28] } & Pipe diameter, $\mathrm{D}(\mathrm{m})$ & 0.8 \\
\hline & Shear strength of soil at mud-line, $\mathrm{sum}_{\mathrm{um}}(\mathrm{kPa})$ & 2.3 \\
\hline & Shear strength gradient, $\mathrm{k}(\mathrm{kPa} / \mathrm{m})$ & 3.6 \\
\hline & Submerged unit weight of soil, $\gamma_{\mathrm{s}}^{\prime}\left(\mathrm{kN} / \mathrm{m}^{3}\right)$ & 6.5 \\
\hline & Young's modulus of soil, $\mathrm{E}_{\mathrm{s}}$ & $500 \mathrm{~s}_{\mathrm{u} 0}$ \\
\hline & Poisson's ratio of soil, $v_{\mathrm{s}}$ & 0.499 \\
\hline & Reference shear strain rate, $\gamma_{\text {ref }}\left(\mathrm{s}^{-1}\right)$ & $3 \times 10^{-6}$ \\
\hline & Vertical pipeline penetration rate, $v_{p v}\left(s^{-1}\right)$ & $0.015 \mathrm{D}$ \\
\hline & Horizontal pipeline penetration rate, $v_{\mathrm{ph}}\left(\mathrm{s}^{-1}\right)$ & $0.05 \mathrm{D}$ \\
\hline & Rate of strength increase per decade, $\mathrm{k}_{\mathrm{t}}$ & 0.1 \\
\hline & Sensitivity of clay, $S_{t}$ & 3.2 \\
\hline & $\begin{array}{l}\text { Accumulated plastic strain at which } 95 \% \text { soil strength reduction occurs } \\
\text { by remoulding, } \xi_{95}\end{array}$ & 10 \\
\hline & Pipe/soil interface shear strength $\tau_{\text {int }}$ & $0.5 \mathrm{~s}_{\mathrm{um}}$ \\
\hline \multirow{11}{*}{ Zhu et al. [32] } & Outside diameter of pipeline $\mathrm{D}(\mathrm{m})$ & 0.65 \\
\hline & Pipe wall thickness $\mathrm{t}(\mathrm{m})$ & 0.015 \\
\hline & Young's modulus of pipeline $E_{p}(\mathrm{GPa})$ & 206 \\
\hline & Poisson's ratio of pipeline, $v_{\mathrm{p}}$ & 0.3 \\
\hline & Coefficient of linear thermal expansion is $\alpha\left({ }^{\circ} \mathrm{C}^{-1}\right)$ & $11 \times 10^{-6}$ \\
\hline & Equivalent pipe weight (including coating) $W_{P}(\mathrm{~N} / \mathrm{m})$ & 3800 \\
\hline & Axial friction coefficients $\mu_{\mathrm{a}}$ & 0.5 \\
\hline & Lateral friction coefficients $\mu_{\mathrm{L}}$ & 0.7 \\
\hline & Limiting value for the axial resistance $\mathrm{k}_{\mathrm{u}}(\mathrm{N} / \mathrm{m})$ & $3800 \times 0.5$ \\
\hline & Limiting value for the lateral resistance $\mathrm{k}_{\mathrm{v}}(\mathrm{N} / \mathrm{m})$ & $3800 \times 0.7$ \\
\hline & Factors determining the initial stiffness $\left(\mathrm{k}_{\mathrm{ou}}\right.$ and $\left.\mathrm{k}_{\mathrm{ov}}\right)(\mathrm{N} / \mathrm{m})$ & 50 \\
\hline
\end{tabular}

\subsection{Buried Pipeline}

Pipelines are often buried within the seabed to protect the pipelines from different hydrodynamic forces $[47,48]$ and also from different human activities such as fishing or transportation. While in some cases, the pipeline is buried under a rubble-mound material, which acts as a protection, e.g., as similarly to [3], in others it may be buried within the actual soil [49]. Burial of pipeline also increases the stability and the thermal insulation of the pipeline. However, the surrounding soil of a buried pipeline provides resistance against the longitudinal thermal expansion of the pipeline. Thus, a longitudinal compressive force is induced within the pipeline, similar to the surface-laid pipeline. Due to this compressive force, a global buckling tendency is further induced within the pipeline. For a buried pipeline, the uplift resistance of the pipeline is usually lesser than the lateral resistance and downward penetration resistance. Thus, the global uplift buckling is the predominant buckling criteria for a buried pipeline [49-59]. However, global lateral buckling was also analysed in some cases as they were believed to be crucial for the pipeline design.

\subsubsection{Global Upheaval Buckling and Upheaval Buckling Resistance}

For a buried pipeline, global upheaval buckling of the pipeline is more critical than the global lateral buckling, as the lateral resistance is greater than the uplift resistance of the pipeline in most cases. Moreover, the upheaval buckling of pipelines often causes collapse of the buried pipelines, for example, the rupture of a buried pipeline at Guanabara Bay of Rio de Janeiro, Brazil [60]. Thus, a significant number of researchers showed interest in exploring the upheaval buckling phenomenon of a buried offshore pipeline $[35,48,52,54,56,59]$. In Figure 10, a schematic diagram of global upheaval buckling of buried pipeline is shown. 


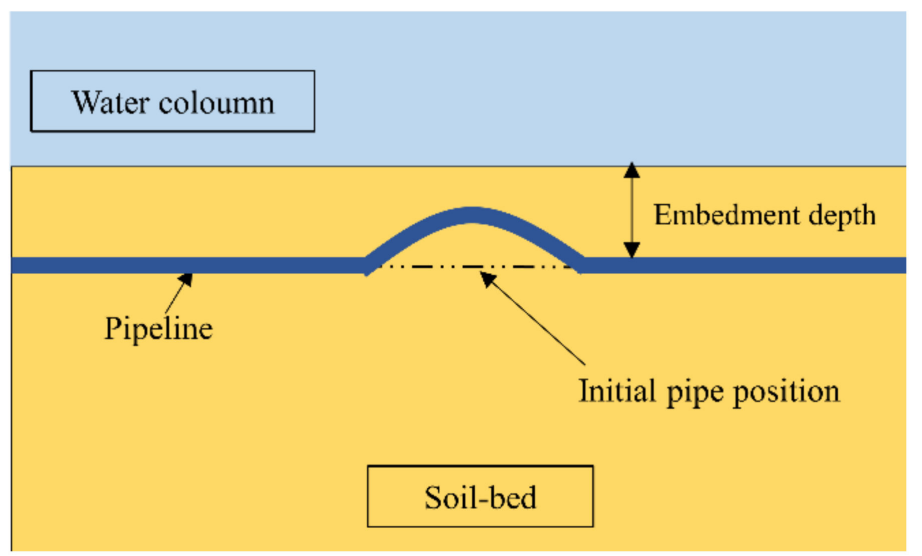

Figure 10. Schematic diagram of global upheaval buckling of buried pipeline.

Analytical Models

Initially, the analysis of the pipeline was started with the analysis of other cylindrical elements such as piles. For example, Randolph and Houlsby [61] investigated the lateral capacity of laterally loaded piles in homogeneous soil. They modelled the piles as cylindrical elements and analysed the model in plane-strain conditions. They explored the lateral capacity of the piles using analytical methods, which yielded that the peak non-dimensionalised load factor was $6+\pi$ for smooth pipe and $4 \sqrt{ } 2+2 \pi$ for the fully rough pipes. Further, it is observed by the other researchers that the behaviour of the piles under lateral displacement is similar to the behaviour of the pipelines under vertical displacement [54,56]. It is also found by the researchers that, for ideal cases (weightless soil and unlimited pipe-soil interface tension), the penetration resistance and uplift resistance $[54,56,58,59]$ of the pipeline reached a peak value of 9.14 for smooth pipes and 11.94 for rough pipes. Several authors observed that soil strength is one of the crucial factors to influence the uplift resistance. They empirically or theoretically developed different models to predict the uplift resistance from undrained or drained soil resistance [62,63]. Thus, according to DNV RP F110 [64], the expression for uplift resistance was given as:

$$
V_{V}=2 s_{U} w+\gamma_{s}^{\prime} A_{s}
$$

Chen et al. [55] found that the soil resistance act as a stabilising force to prevent the pipeline from uplifting. Moreover, the stabilising force is linearly related to the normalised average shear strength of soil, as can be seen from the expression proposed by them,

$$
\mathrm{F} \frac{V_{V \max }}{\gamma_{w} \frac{\pi D^{2}}{4}}=\frac{0.25 \gamma_{s}^{\prime} D}{C_{u}}+0.78
$$

The predicted results from the given expression were also compared with the experimentally obtained results. A discrepancy was obtained between the two results because of lack of knowledge of the type of soil failure mechanism.

Several authors also involved the interface tensile capacity of the pipe-soil interface to predict the uplift resistance of the pipeline [35,52,56]. The uplift force per unit length of the pipeline was derived by Cheuk et al. [35] using a simple model, and the expressions can be given as,

For fully undrained and fully bonded conditions,

$$
\begin{gathered}
P_{v}=\left[4\left(w+\frac{D}{2}\right)+\frac{11 D}{\sqrt{3}}\right] s_{u, a v e} D \\
=\left(\frac{4 w}{D}+8.35\right) s_{u, a v e} D
\end{gathered}
$$


For fully undrained and fully unbonded conditions,

$$
\begin{gathered}
P_{v, \text { total }}=W_{s}+W_{p}+2 w s_{u, a v e}-\gamma_{w}\left(A_{\text {soil }}+\frac{\pi D^{2}}{4}\right)+F_{s} \\
=W_{s}^{\prime}+W_{p}^{\prime}+2 w s_{u, a v e}+P_{\text {suction }} \\
P_{v}=P_{v, \text { total }}-W_{p}^{\prime}
\end{gathered}
$$

For fully drained conditions,

$$
\begin{gathered}
P_{v, \text { total }}=W_{s}^{\prime}+W_{p}^{\prime}+2 w \tau_{u, \text { ave }} \\
P_{v}=P_{v, \text { total }}-W_{p}^{\prime}
\end{gathered}
$$

Again, from several small strain finite element analyses, Maitra et al. [56] proposed a model to predict the undrained upheaval capacity of buried pipelines for a practical range of parameters under the immediate breakaway and no separation condition. They produced the expressions through curve fitting and error minimisation by the least square method and using the numerically obtained data. The expressions for uplift capacity factors were given as;

For no tension condition,

$$
N_{u}=\frac{V_{u}}{S_{u, e f f} D}=N_{u(\text { weightless })}+\left(\frac{W_{\text {soil }}}{S_{u, e f f} D}\right)
$$

For full tension condition,

$$
N_{u}=\frac{V_{u}}{S_{u, e f f} D}=N_{u(\text { weightless })}-\left(\frac{\gamma_{s}^{\prime}}{S_{u, e f f} D}\right) A
$$

where, for homogeneous soil

$$
s_{u, e f f}=s_{u}
$$

However, for normally consolidated soil $\left(S_{u}=k Z\right)$,

$$
\begin{array}{ll}
s_{u, e f f}=f_{N B A} k\left(w+\frac{D}{2}\right) & \text { FT condition } \\
s_{u, e f f}=f_{B A} k\left(w+\frac{D}{2}\right) & \text { NT condition }
\end{array}
$$

Again,

$$
f_{N B A}=\frac{1}{\left[1-\exp \left(-\lambda_{1}\left(1+\frac{w}{D}\right)^{\lambda_{2}}\right)\right]} f_{B A}=\left[1-\exp \left(-\lambda_{3}\left(1+\frac{w}{D}\right)^{\lambda_{4}}\right)\right]
$$

The prediction model was further validated with available experimental and analytical models, and it is observed that the proposed model predicted results with a maximum error of less than $8 \%$.

Moreover, Newson and Deljoui [52] performed a parametric study using FE analysis to investigate the failure mechanism and its transition from shallow to deep shear failure and pull-out forces of a pipeline buried within a seabed. According to the authors, the total ultimate uplift force of the pipeline was given as:

$$
V_{t}=V_{u}+W_{p}
$$

Again, $W_{u}$ can be given as, for no tension condition

$$
\frac{V_{u}}{\gamma_{s}^{\prime} w D}=1+0.1 \frac{D}{w}+\frac{2 c_{u}}{\gamma_{s} / w}\left(\frac{w}{D}+\frac{1}{2}\right)
$$


and for deep shear failure and full tension condition.

$$
V_{u}=N_{c} \mathcal{C}_{u} D
$$

They also performed a FE analysis for comparison with the analytical model. Furthermore, the predicted results using analytical relationships showed consistency with the FE analysis results. It is also observed that the uplift capacity factor values are $4.5-6.5 \%$ greater than that of a strip anchor [65].

Furthermore, the soil around the pipe gets liquefied during the pipe installation using jetting method. Thus, some researchers also considered the effect of consolidation of the liquefied soil on the pipe uplift resistance. Bransby et al. [51] proposed a model to predict the uplift capacity of a pipeline buried in liquefied soil from the average degree of consolidation of the pipeline. The uplift capacity was given as,

$$
V_{u}=N_{p} c_{u} D
$$

and in normalised form,

$$
\frac{V_{u}}{\gamma_{s}^{\prime} w D}=N_{p} \frac{c_{u}}{\gamma_{s}^{\prime} w}
$$

The authors found that $\mathrm{cu}$ is proportional to the effective stress in the backfill $\left(\sigma_{\mathrm{v}}{ }^{\prime}\right)$, which was further given by,

$$
\sigma_{v}^{\prime}=U \gamma^{\prime} Z
$$

The proposed prediction model was compared with experimental studies, and both of them showed a good agreement. Thus, the prediction model was claimed to be used in the initial pipe design. However, detailed experimental studies were prescribed in advanced stage of design.

Furthermore, Schaminee et al. [50] developed simplified models to predict the uplift resistance of a pipeline buried in cohesionless soil. Thus, the uplift resistance for the pipe can be given as;

$$
V_{u}=\gamma_{s}^{\prime} w D+w^{2} \gamma_{s}^{\prime} \tan \phi
$$

again, the uplift resistance for pipes buried in a cohesive soil,

$$
V_{u}=\gamma_{s}^{\prime} w D+2 w c_{u}
$$

The proposed simplified model agrees well with the experimental studies performed by the authors and can be used for design and integrity assessment of pipelines.

Liu et al. [66] proposed an empirical non-linear force-displacement relation from the laboratory test results. The expressions are valid for Bohai soft clay (Bohai, China) or soils having similar properties. According to the authors, the maximum uplift resistance and the corresponding axial displacement were given as,

$$
\begin{aligned}
& \frac{V_{u, \text { max }}}{s_{u} D}=1.62\left(\frac{w}{D}\right)^{0.58} \\
& \frac{\delta_{u, \max }}{D}=0.2\left(\frac{w}{D}\right)^{0.22}
\end{aligned}
$$

Again the uplift resistance $(V u)$ was given as,

$V u=\left\{\begin{array}{l}V_{u, \max }\left(\frac{\delta_{u}}{\delta_{u, \max }}\right)^{b 3} \quad \text { for } \delta_{u} \leq \delta_{u, \max } \\ V_{u, \max }\left(1-\left(\frac{\delta_{u}-\delta_{u, \max }}{w}\right)\right)^{0.4} \quad \text { for } \delta_{y}>\delta_{y, \max }\end{array}\right.$

where, $b_{3}=0.15$ for $w / D \leq 4 ; b_{3}=0.2$ for $w / D>4$. 
The results obtained using Equations (47) and (48) are shown in Figure 11. The results are also compared with the result obtained using DNV RP-F110 [62] and experimental means. It is observed that Equations (47) and (48) overestimate the uplift resistance in comparison to experimental results.

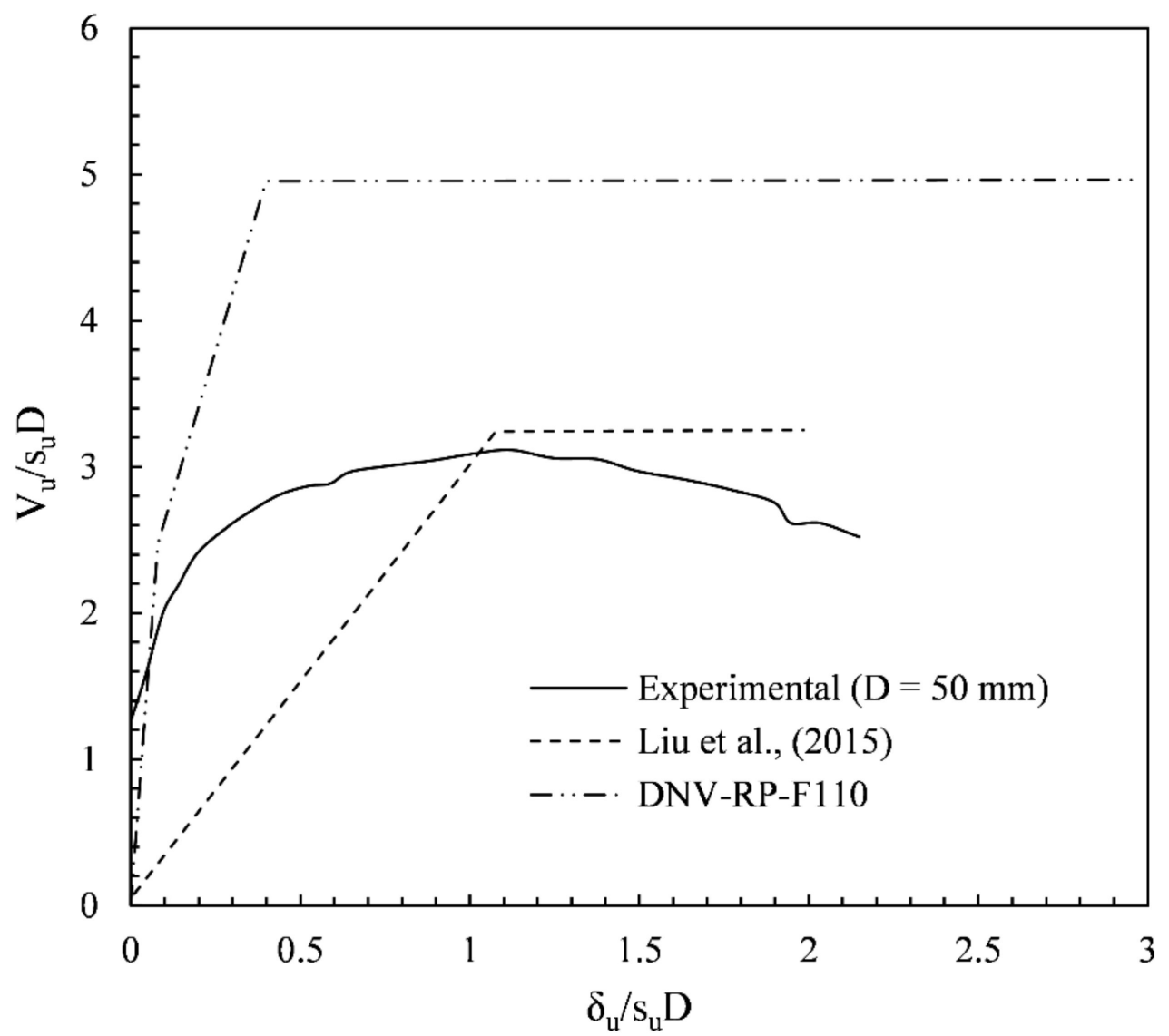

Figure 11. Comparison of uplift resistance vs uplift displacement behaviour for different methods of analysis [66].

Gao et al. [67] performed a large scale model test, and the results are used to model the soil as a non-linear spring, and further, the behaviour of the soil was numerically studied for the uplift of the pipeline. The researchers developed expressions to calculate the maximum uplift and axial resistance by taking references from the available models $[50,68]$ and using the experimentally obtained data. For uplift resistance, two different models were considered. For higher embedment depth (w/D > 5), the soil was modelled using elasticity plasticity model, while for shallow embedment depth $(\mathrm{w} / \mathrm{D} \leq 5)$, the soil was modelled as elasticity softened model. However, to study the axial resistance of pipelines, elasticity plasticity model was used. The expressions were given as,

$$
\begin{array}{cc}
V_{u, \max }=\gamma_{s}^{\prime}\left(w D+1.16 w^{2}-0.13 \frac{w^{2}}{D}\right) & w / D \leq 5 \\
V_{u, \max }=\gamma_{s}^{\prime} w D\left(1+0.1 \frac{D}{w}+A_{1} \frac{w}{D}\right) & w / D>5
\end{array}
$$

While Wang et al. [69] developed a numerical model to explore the effect of cover depth on the load-displacement behaviour of the pipeline. They also studied the effect of axial and uplift resistance on the localised upheaval buckling behaviour. They also compared the results with various available studies. It is observed that both the buckle length and amplitude decreased with increasing cover height. Moreover, the buckle 
amplitude decreased with increasing uplift soil resistance. The safe temperature was observed to decrease with an increasing rate of deterioration of the uplift resistance from peak value to the residual value.

\section{Numerical Models}

The authors studied the global uplift buckling of a pipeline using different numerical 2D and 3D models $[54,56,59,70]$. The failure mechanisms, load-displacement behaviour, and the capacity factors of the pipelines were studied numerically, and their dependency on the different soil properties and pipe-material properties were also explored. Moreover, the analysis was performed for both cohesive [52,54-56,70,71] and cohesionless backfill [72-79].

For cohesionless backfill, it was observed that the uplift resistance increased with increasing embedment depth $(\mathrm{w})$ and displacement $\left(\delta_{\mathrm{u}}\right)$ of the pipeline, as can be seen from Figure 12. Again, it was considered by DNV RP F110 [62] and ASCE guidelines that the displacement corresponding to the peak pipe resistance $\left(\delta_{\mathfrak{u}, \max }\right)$ was hardly affected by the embedment depth for cohesionless backfill. While one researcher [77] observed that the displacement corresponding to the peak pipe resistance was significantly affected by the embedment depth ratio, especially for embedment depth $(\mathrm{w})$ beyond $0.5 \mathrm{~m}$. Moreover, $\delta_{u, \max }$ was observed to decrease with an increasing relative density of soil and increase with increasing ' $w$ ' $[72,78,79]$. The failure surface or the slip surface was observed to reach the ground surface when peak uplift resistance is mobilised for shallow embedment depth. In contrast, the slip surface was localised around the pipeline and did not reach the ground surface for deeper embedment depth [78,79].

However, for cohesive backfill, the pipe displacement can happen either in no tension condition or full tension condition, depending on the pipe-soil interface capacity. The behaviour of $N_{u}$ is portrayed in Figure 13. It is observed that the uplift capacity factor $\left(N_{u}\right)$ increased with increasing embedment depth ratio (w/D) for both no tension (NT) and full tension (FT) conditions. Again, for NT condition, the $N_{u}$ was observed to be increasing with increasing soil unit weight. On the contrary, for FT condition, $N u$ was observed to decrease with increasing soil unit weight due to the buoyancy effect, as can be seen in Figure $13[54,56,59,66]$. However, for very high weight to strength ratio of the soil, the pipe-soil contact did not break. Thus, the pipeline's uplift resistance did not depend on the interface tensile capacity.

Furthermore, a typical failure mechanism of soil during pipe uplift is shown in Figure 14. In Figure 14a, the uplift failure mechanism of pipeline buried under shallow embedment depth is shown, while in Figure 14b, the failure mechanism for a deeply embedded pipeline is shown. Thus, from Figure 14, it is observed that most displacements occurred within the soil volume above the pipeline for a shallowly embedded pipeline. While for the bonded case, the displacement extended both above and below the pipeline. Again, the failure is very localised and occurs close to the pipeline for a deeply embedded pipeline $[52,56,59]$. 


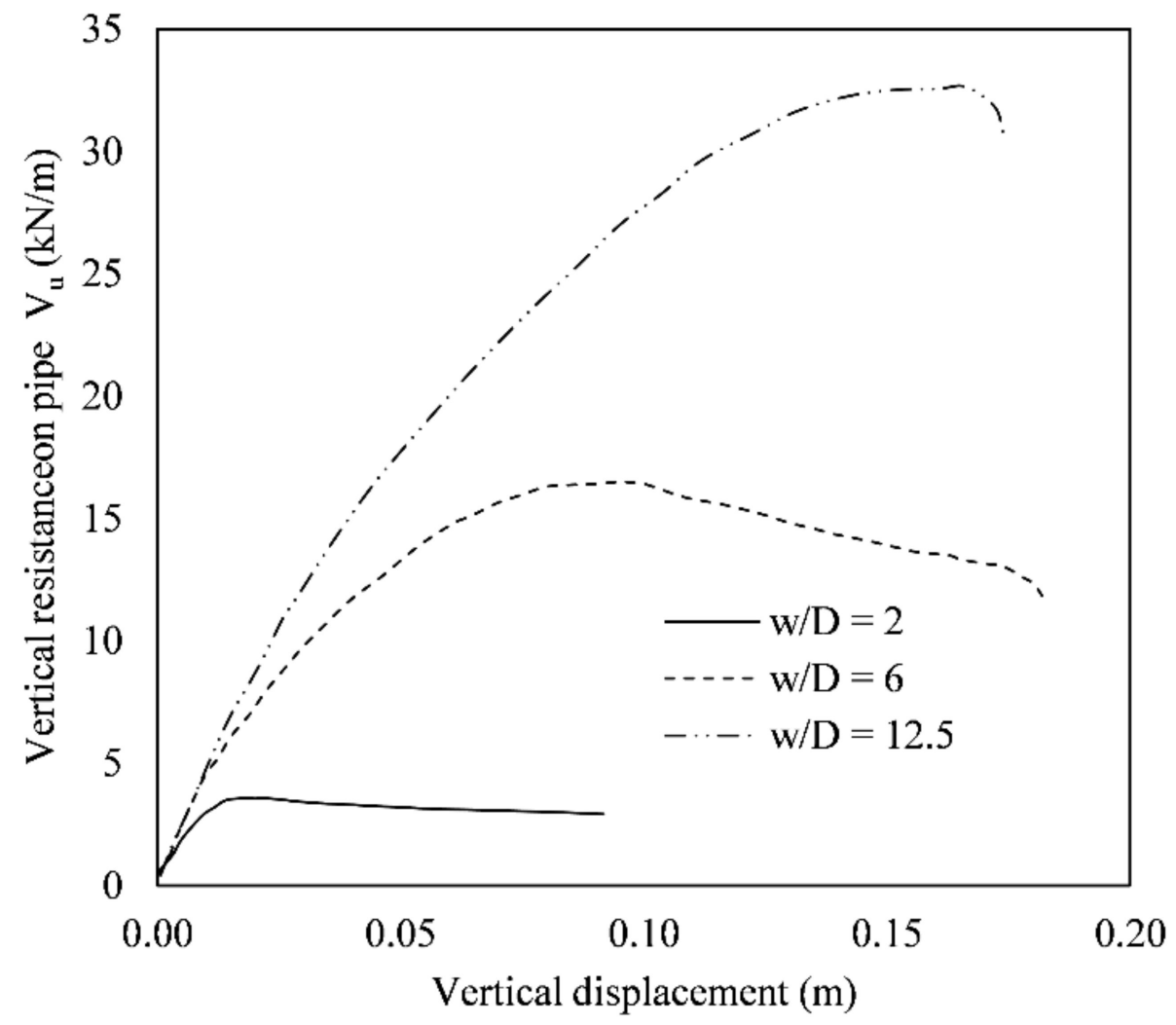

Figure 12. Variation of uplift resistance with displacement for various embedment depths [77].

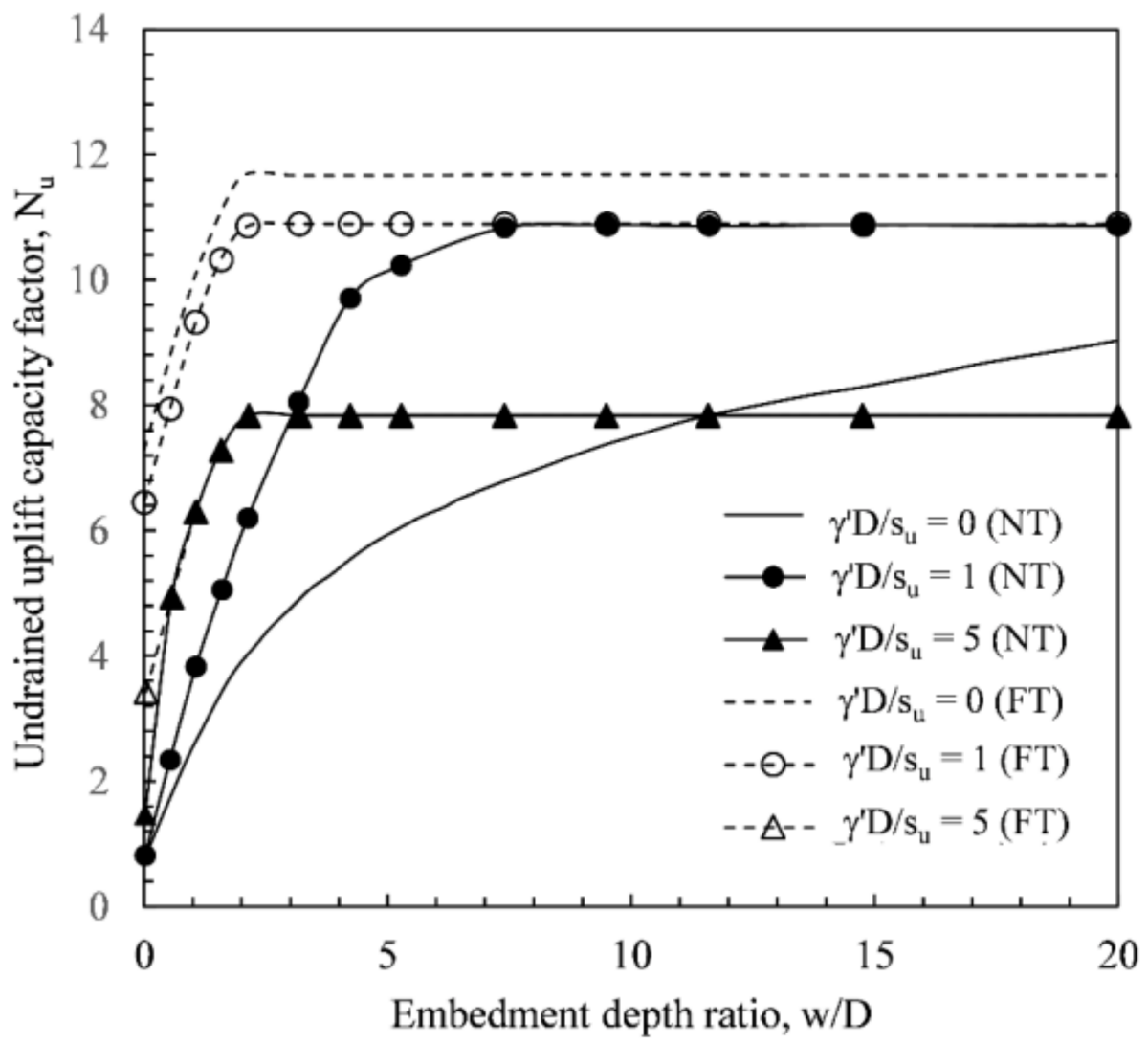

Figure 13. Variation of uplift resistance with soil cover depth and soil unit weight for both NT and FT conditions and for rough pipeline surface [56]. 


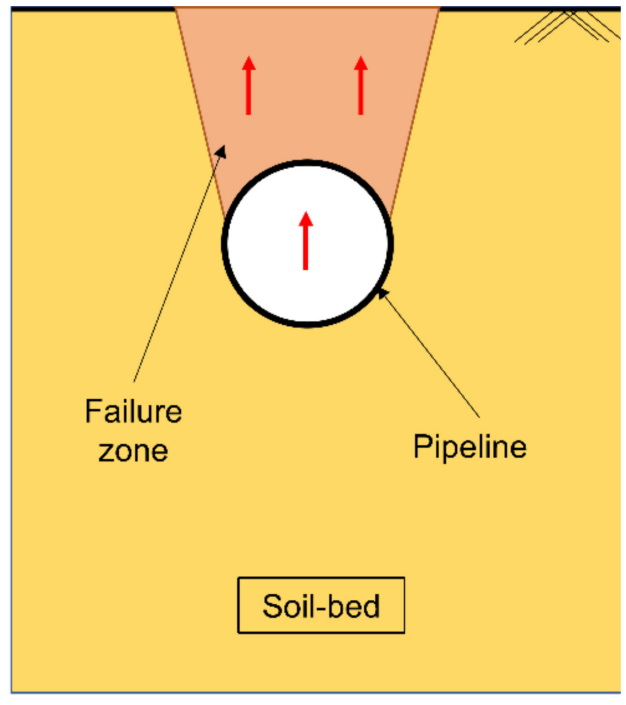

(a)

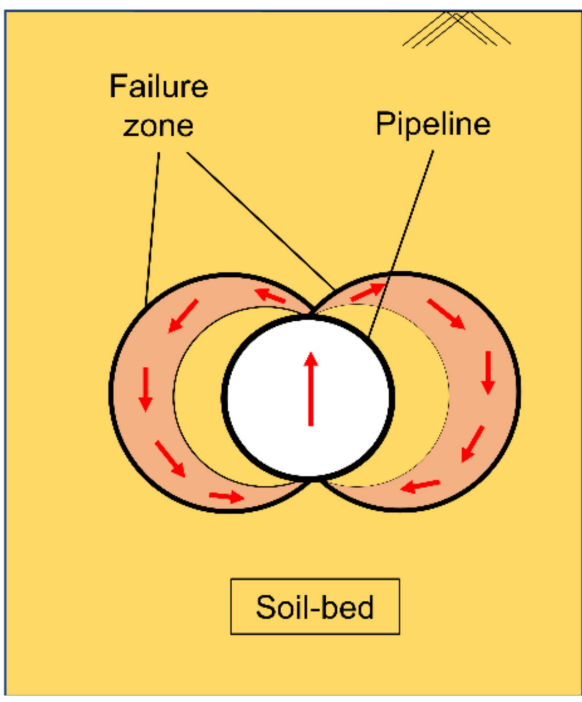

(b)

Figure 14. Typical displacement contour for soil failure for (a) shallow and (b) deeply embedded pipeline during pipe uplifting in NT condition, a conceptual diagram from the FEA generated displacement contour [59].

Several authors also studied the effect of initial imperfection on the pipeline global buckling $[66,67,80]$. It is observed that the uplift resistance decreased with increasing initial imperfection. Moreover, the global uplift buckling of a pipeline can effectively be controlled by increasing cover height or reducing the imperfection height.

The details of the parameters considered by different authors for the numerical analysis are given in Table 3.

Table 3. Parameter used in the Numerical models for uplift resistance of buried pipeline.

\begin{tabular}{|c|c|c|}
\hline Author & Parameter & Magnitude \\
\hline \multirow{4}{*}{$\begin{array}{c}\text { Newson and } \\
\text { Deljoui [52] }\end{array}$} & Modulus of elasticity of soil $E_{s}(\mathrm{kPa})$ & $\begin{array}{c}100 c_{u} \\
(4000 \text { in most cases) }\end{array}$ \\
\hline & Poisson's ratio of soil, $v_{s}$ & 0.495 \\
\hline & Undrained shear strength $s_{u}(\mathrm{kPa})$ & 10 \\
\hline & Depth to diameter ratio, $w / D$ & $1-15$ \\
\hline \multirow{5}{*}{$\begin{array}{l}\text { Martin and } \\
\text { White [54] }\end{array}$} & Embedment depth ratio $w / D$ & $0.1-5$ \\
\hline & Dimensionless weight to strength ratio for homogeneous soil $\left(\gamma_{s}{ }^{\prime} D / s_{u}\right)$ & $0,1,3,5$ \\
\hline & Dimensionless weight to strength ratio for normally consolidated soil $\left(\gamma_{s}^{\prime} / k\right)$ & $0,1,3,5$ \\
\hline & Interface roughness for smooth and rough pipe & 0 and 1 \\
\hline & Interface tensile capacity for no tension condition and unlimited tension $(\mathrm{kPa})$ & 0 and infinite \\
\hline \multirow{7}{*}{ Maitra et al. [56] } & Embedment depth ratio $w / D$ & $\begin{array}{c}0,0.5,1,1.5,2,3,4,5,7,9,11 \\
14,19\end{array}$ \\
\hline & Dimensionless weight to strength ratio for homogeneous soil $\left(\gamma_{s}^{\prime} D / s_{u}\right)$ & $\begin{array}{c}0,0.1,0.2,0.3,0.4,0.5,0.75,1, \\
2,3,4,5\end{array}$ \\
\hline & Dimensionless weight to strength ratio for normally consolidated soil $\left(\gamma_{s}^{\prime} / k\right)$ & $0,1,2,5,10,20,50$ \\
\hline & Modulus of elasticity of soil $E_{S}(\mathrm{kPa})$ & $500 \mathrm{su}$ \\
\hline & Poisson's ratio of soil, $v_{s}$ & 0.499 \\
\hline & Interface roughness for smooth and rough pipe & 0 and 1 \\
\hline & Interface tensile capacity for no tension condition and unlimited tension $(\mathrm{kPa})$ & 0 and infinite \\
\hline
\end{tabular}


Table 3. Cont.

\begin{tabular}{|c|c|c|}
\hline Author & Parameter & Magnitude \\
\hline Seth et al. [59] & $\begin{array}{c}\text { Pipe } \\
\text { Outer diameter } \mathrm{D},(\mathrm{m}) \\
\text { In-plane axial stiffness } \mathrm{EA}_{1}(\mathrm{kN} / \mathrm{m}) \\
\text { Out of the plane axial stiffness EA }(\mathrm{kN} / \mathrm{m}) \\
\text { Flexural rigidity EI }\left(\mathrm{kN} \mathrm{m}^{2} / \mathrm{m}\right) \\
\text { Soil } \\
\text { Undrained shear strength at the soil surface } \mathrm{S}_{\mathrm{u}, \mathrm{ref}}\left(\mathrm{kN} / \mathrm{m}^{2}\right) \\
\text { Incremental shear strength with depth } \mathrm{k}\left(\mathrm{kN} / \mathrm{m}^{2} / \mathrm{m}\right) \\
\text { Normalised effective soil weight }\left(\gamma_{\mathrm{s}}^{\prime} / \mathrm{k}\right) \\
\text { Soil cover depth ratio }(\mathrm{w} / \mathrm{D}) \\
\text { Stiffness index }\left(\mathrm{E}_{\mathrm{s}} / \mathrm{s}_{\mathrm{u}}\right) \\
\text { Poisson's ratio of soil }\left(\nu_{\mathrm{s}}\right)\end{array}$ & $\begin{array}{l}1 \\
7.8 \times 10^{6} \\
6.225 \times 10^{6} \\
5265 \\
\\
0.01 \\
2 \\
0,1,2,5,10 \\
0-20 \\
500 \\
0.495 \\
0 \text { and } 10^{7}\end{array}$ \\
\hline
\end{tabular}

Experimental Models

A significant number of experiments were performed to observe the pipe-soil interaction, failure mechanism and the behaviour of some other relevant factors during pipe uplift. Some of the experiments were performed using centrifuges $[51,57,67,81]$ and the others under normal earth's gravity using full-scale models [50,55,66,67]. Moreover, several researchers also explored the failure mechanisms and the load-displacement behaviour of the pipeline using image-based deformation measurement technique $[30,38,81,82]$.

For cohesionless backfill, the maximum uplift resistance was observed to increase with increasing embedment depth, soil density, and pipe diameter. However, the uplift capacity factor decreased with increasing pipe diameter [50,51,67,72,83-85]. Again, the uplift resistance initially increased with increasing displacement until reaching the peak value. Moreover, the uplift resistance decreased rapidly with increasing displacement in post-peak conditions $[67,72,85,86]$. Furthermore, it is observed that failure block forms between two shear zones during peak uplift capacity mobilisation $[50,72,81]$. The width of the shear zones is influenced by the grain size of the backfill. For a typical offshore pipeline, the failure mechanism corresponding to the peak uplift capacity is observed to reach the ground surface. While a flow around mechanism of soil was observed at post-peak condition [81].

However, for a pipeline buried in soft or lumpy clay, the behaviour of the pipeline also depends on the loading rate and the consolidation time. Thus, two types of behaviour are observed for the pipelines buried in a lumpy clay, namely short-term and long-term behaviour $[18,50,51,55,57,81,87]$. The uplift resistance was observed to be increasing linearly with displacement up to a peak resistance value. Moreover, the peak resistance of the pipeline is observed to increase with increasing uplifting speed. Again, the uplift capacity for the undrained test was higher than that for a drained test. It is observed that the displacement corresponding to the maximum uplift capacity of the pipeline increased with increasing pipe diameter and the embedment depth. With increasing time, the soft soil consolidated, and the uplift resistance is observed to increase with increasing soil consolidation [18,50,51,66,81]. Again, Brennan et al. [57] observed that the uplift capacity of the pipeline increased with increasing size of clay lumps, irrespective of the speed of uplifting. Furthermore, for shallowly embedded pipelines, the plastic zone concentrated on the shoulder of the pipeline and extended upward. In contrast, for the deeply embedded pipeline, the plastic zone concentrated on the whole crown of the pipe and extended only over the pipeline [55].

\subsubsection{Global Lateral Buckling and Lateral Buckling Resistance}

For a buried pipeline, the chances of global lateral buckling are not very high. Still, in some cases such as lateral soil movement or for some particular interface conditions, the 
global lateral buckling of pipeline can be critical. The following are some studies performed by several researchers to explore the response of buried pipelines under lateral loading.

Analytical Models

Rowe and Davis [65] theoretically derived a formula to calculate the bearing capacity of an anchor buried in sand for its vertical and lateral movement. The developed expression was often used to compare with the lateral or uplift capacity of buried pipeline [18]. The expression can be given as:

$$
q_{u}=f_{\gamma} \gamma h
$$

Moreover, the authors also extended the theoretical model for cohesive soil and the expression was given as:

$$
q_{u}=c^{\prime} f_{c^{\prime}}+f_{\gamma} \gamma_{s}^{\prime} w_{h}
$$

The theoretical results were compared with the model test results and field data, and they showed a good match. Thus, the theoretical model provides a rational prediction of anchor capacity.

Phillips et al. [88] studied the load-displacement behaviour of a pipeline trenched within a cohesive soil under lateral displacement. They proposed a numerical model to analyse the lateral displacement of a pipeline. An expression for maximum lateral resistance was given as,

$$
V_{H, \max }=c_{u} N_{c h} D
$$

The analytical model showed good agreement when compared with the results obtained from several large-scale experiments and previous prediction models $[65,89]$. Moreover, several researchers also explored the effect of trench on the uplift resistance of the pipeline $[90,91]$.

\section{Numerical Models}

Numerical analyses were also performed to investigate the behaviour of a buried pipeline under lateral loading. Seth et al. [59] performed a finite element analysis to observe the failure mechanism and load-displacement behaviour of a buried pipeline subjected to lateral and vertical displacements individually. They also compared the lateral and uplift capacity factors for different interface conditions to observe the criticality of the factors. As can be seen from Figure 15, the lateral capacity factor increased with increasing embedment depth and soil unit weight for NT condition. Similarly, the relationship between lateral capacity factor and embedment depth and soil unit weight for FT condition are shown in Figure 15. It is observed that the lateral capacity factor increased with increasing embedment depth for full tension condition. However, it remained constant with increasing soil unit weight. Lateral capacity was observed to be critical for full tension condition and small soil unit weight. The rotation of stress vectors during deep shear failure was also observed from the stress contours. The parameters used in the numerical analysis are given in Table 4 . 


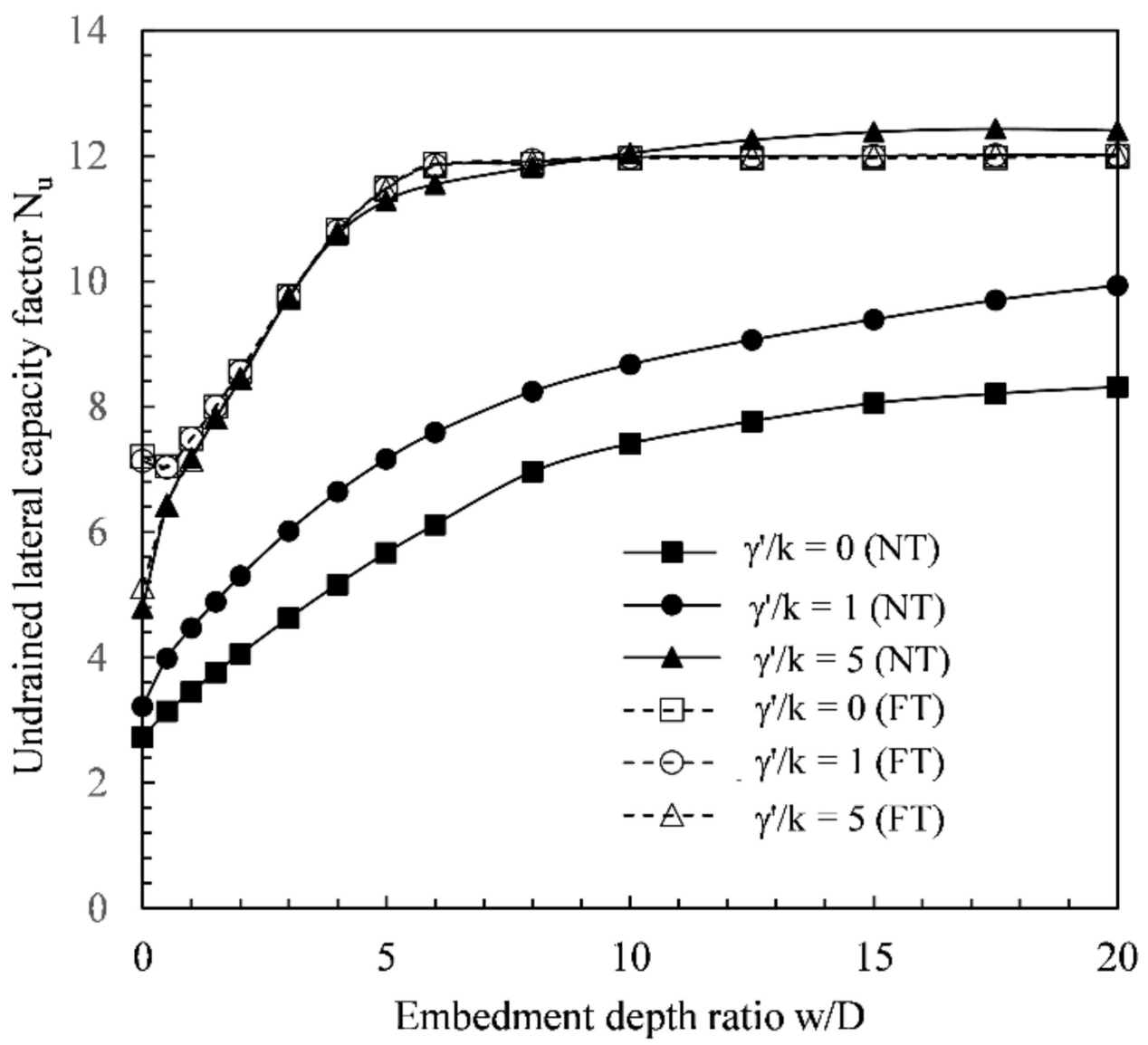

Figure 15. Influence of soil cover depth and soil unit weight on lateral capacity factor of an offshore pipeline under NT and FT condition [59].

Table 4. Parameter used in the Numerical models for lateral resistance of buried pipeline.

\begin{tabular}{|c|c|c|}
\hline Author & Parameter & Magnitude \\
\hline \multirow{13}{*}{ Seth et al. [59] } & Pipe & \\
\hline & Outer diameter D, (m) & 1 \\
\hline & In-plane axial stiffness $\mathrm{EA}_{1}(\mathrm{kN} / \mathrm{m})$ & $7.8 \times 10^{6}$ \\
\hline & Out of the plane axial stiffness $\mathrm{EA}_{2}(\mathrm{kN} / \mathrm{m})$ & $6.225 \times 10^{6}$ \\
\hline & Flexural rigidity $\mathrm{EI}\left(\mathrm{kN} \mathrm{m} \mathrm{m}^{2} / \mathrm{m}\right)$ & 5265 \\
\hline & (1) & \\
\hline & $\begin{array}{l}\text { Undrained shear strength at the soil surface } S_{\mathrm{u} \text {,ref }} \\
\qquad\left(\mathrm{kN} / \mathrm{m}^{2}\right)\end{array}$ & 0.01 \\
\hline & $\begin{array}{l}\text { Incremental shear strength with depth } \mathrm{k} \\
\qquad\left(\mathrm{kN} / \mathrm{m}^{2} / \mathrm{m}\right)\end{array}$ & 2 \\
\hline & Normalised effective soil weight $\left(\gamma_{\mathrm{s}}^{\prime} / \mathrm{k}\right)$ & $0,1,2,5,10$ \\
\hline & Soil cover depth ratio (w/D) & $0-20$ \\
\hline & Stiffness index $\left(\mathrm{E}_{\mathrm{s}} / \mathrm{s}_{\mathrm{u}}\right)$ & 500 \\
\hline & Poisson's ratio of soil $\left(v_{s}\right)$ & 0.495 \\
\hline & $\begin{array}{l}\text { Interface tensile capacity for no tension condition } \\
\text { and unlimited tension }\end{array}$ & 0 and $10^{7}$ \\
\hline
\end{tabular}

\section{Experimental Models}

The authors experimentally studied the buried pipeline's global lateral buckling behaviour, either using full-scaled models [18,92,93] or centrifugal models [88,94].

It was observed from the large-scaled tests that the normalised lateral resistance increased with increasing pipeline displacement, and also, at the initial stage, the higher 
normalised lateral resistance was observed to be higher for larger pipe diameter. Moreover, the rate of increase in the normalised lateral resistance decreased with increasing pipe diameter, which led the authors to believe that the normalised lateral resistance assumes a constant peak value irrespective of the pipeline's embedment depth. Again, the normalised lateral resistance was initially increasing with increasing embedment depth of the pipeline and remained constant after reaching the peak value [18,92,93].

Again, from the centrifugal tests [88,94], it was observed that the lateral resistance increased with increasing pipe displacement up to a peak value and then remained constant or decreased. Moreover, the lateral resistance was also observed to be increasing with increasing embedment depth ratio. It was also observed that with increasing trench width, the lateral loading on the pipeline decreases.

\section{Studies on Axial Soil Resistance and Its Importance in the Pipeline Global Buckling}

A high pressure-high temperature $(\mathrm{HP} / \mathrm{HT})$ pipeline tends to expanse longitudinally under very high temperature and pressure of the fluid flowing through the pipeline. However, the axial resistance provided by the soil resists the pipeline to move in the axial direction and induce a longitudinal compressive load on the pipeline. Which further induce a global buckling to the pipeline. Thus, the knowledge of axial resistance is crucial for the study of pipe buckling [18]. The following studies validate the importance of axial soil resistance on the pipe buckling analyses. A great number of numerical analyses were performed to observe the effect of axial soil resistance on the pipe buckling [18,30,32,67,69]. It was observed that both the buckling amplitude and the axial force on the pipeline decreased with increasing axial resistance of the soil [31,69]. Moreover, the safe temperature was reduced as the axial friction decreased. This implied that the temperature at which the pipe-buckling occurs decreased with decreasing axial friction.

Again, Hobbs [95] and Hobbs and Liang [96] developed an expression to predict the lateral capacity of a pipeline laid on a rigid seabed in perfectly straight condition. They included the effect of axial resistance. The expression can be given as,

$$
P=\frac{34.06 E_{s} I}{L^{2}}+1.294 \mu_{a} W_{p} L\left[\left(1+1.668 \times 10^{-4} \frac{E_{s} A \mu_{1}{ }^{2} W_{p} L^{5}}{\mu_{a}\left(E_{S} I\right)^{2}}\right)^{0.5}-1\right]
$$

Thus, the axial compressive force on the pipeline was observed to be directly proportional to the axial soil resistance.

Considering the importance of the axial resistance on the buckling behaviour of the pipelines, various researchers took an interest in the exploration of the axial resistance of the soil $[18,31,50,66,67,92,97]$. From various large-scale experiments, it was observed that the axial resistance increased with increasing displacement until reaching the peak value for both cohesionless and cohesive backfill. Moreover, the displacement corresponding to the maximum axial resistance increased with increasing pipe diameter [18,66,92]. However, the influence of cover geometry on the axial resistance was insignificant. The axial resistance was observed to reduce for cyclic reversal of the displacement. One study [18] found that the reduction in axial resistance during cyclic displacement is 38-55\%. Several authors also explored the post-buckling behaviour of axial soil resistance [50]. It was observed that the axial resistance decreased to the residual value at post-peak condition for cohesive backfill. On the contrary, for cohesionless soil, the axial resistance stayed almost constant at the post-peak condition.

Again, Schaminee et al. [50] developed simplified models to predict the axial and uplift resistance of a buried pipeline. The axial resistance for pipes buried in cohesionless soil was given by,

$$
V_{a}=\frac{1}{4} \pi \gamma_{s}^{\prime} w D\left(2+2 K+\frac{W_{p}}{\gamma_{s}^{\prime} w D}+\frac{K D}{w}\right) \tan \theta+\alpha_{a} \pi D c_{u}
$$


Moreover, Liu et al. [66] performed a series of axial pull out tests of a scaled model of a pipeline buried in soft clay. They further proposed an empirical relation from the laboratory test results to predict the peak axial resistance and the corresponding axial displacement. The authors performed laboratory tests on soil which have similar properties as Bohai (China) Soft clay. Thus, the maximum axial resistance and the corresponding displacement were given as,

$$
\begin{gathered}
\frac{V_{H, \max }}{\pi s_{u} D}=0.2 \\
\frac{\delta_{H, \max }}{D}=0.1 D^{0.7}
\end{gathered}
$$

Again, the axial resistances $\left(F_{a}\right)$ was given as,

$V a=\left\{\begin{array}{l}V_{a, \max }\left(\frac{\delta_{a}}{\delta_{a, \max }}\right)^{0.1} \quad \text { for } \delta_{a} \leq \delta_{a, \max } \\ V_{a, \max } \text { for } \delta_{a}>\delta_{a, \max }\end{array}\right.$

The predicted results obtained using the above equations (Equations (58) and (59)) are shown in Figure 16. The predicted axial resistances were further compared with the results obtained using the prediction model given by American Lifeline Alliance [98], and also with the experimental results.

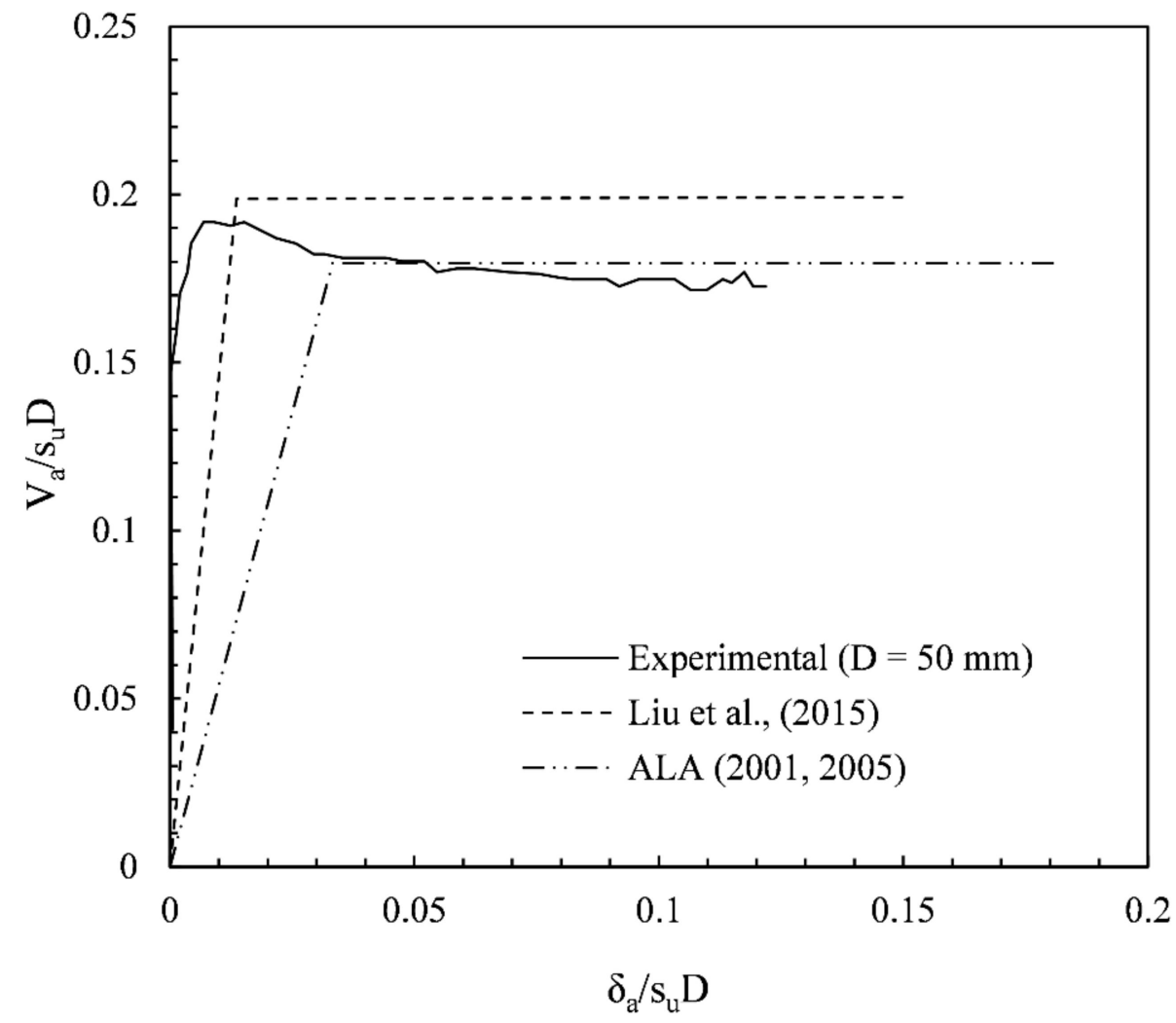

Figure 16. Comparison of axial resistance vs axial movement behaviour for different methods of analysis [66].

Peng [68] assumed that the axial resistance on the pipeline was due to the weight of the overburdened soil and the self-weight of the soil. Thus they developed the following expression,

$$
V_{a}=\mu\left(2 \gamma_{s}^{\prime} D w+W_{p}\right)
$$

Gao et al. [67] performed several large scale experiments and used the results to formulate a non-linear pipe-soil model. They also modified the expression given by 
Peng [68] to give an expression for axial resistance of a pipeline buried in cohesionless soil and subjected to global upheaval buckling. The expression was given as,

$$
V_{a}=A_{2}\left(2 \gamma D w+W_{p}\right) \mu
$$

where, $A_{2}=$ The modification coefficient of the normal stress on the pipeline and is experimentally determinate.

Hence, the initial part of this section discusses the importance of axial resistance on different aspects of pipe-buckling. From different numerical $[18,31,32,67,69]$ and analytical studies $[95,96]$, it is clear that the axial resistance critically influences the buckling amplitude, buckling length, and safe temperature and axial compressive stress leading to pipe buckling. Thus, in the latter part of this section, the expressions to estimate the axial soil resistance and the factors affecting the axial resistance are explored [50,66-68]. It was observed that the axial resistance is influenced by pipe parameters such as pipe diameter and submerged weight of the pipe. Moreover, the axial resistance is also influenced by soil parameters such as soil unit weight, pipe-soil friction coefficient (cohesionless soil), embedment depth, and undrained shear strength (cohesive soil) of soil. A sensitivity analysis is needed to establish the order of importance among the influence factors.

\section{Studies on the External Loads on the Pipeline and Their Effect on Pipeline Local Buckling}

During operation and installation of offshore pipelines, various loads induce within the pipeline. The major loads that act on the pipeline are external pressure, bending, and tension. Among these three types of loading, external pressure and bending can be critical for the collapse of a pipeline under local buckling of pipeline. Thus, in this section, the effects of the external pressure and bending moment on an offshore pipeline are discussed.

\subsection{External Pressure}

The offshore pipelines are operated under very deep water-column. Thus, very high hydrostatic pressure is subjected (can easily be calculated as $\mathrm{ph}=\rho_{\mathrm{w}^{\prime}} \mathrm{g} \mathrm{Z}_{\mathrm{w}}$ ) to the pipeline. Therefore, the external pressure can be critical during installation and depressurisation. The buckling pressure of a perfect pipeline under external pressure was explored by Kyriakides and Corona [99]. Several authors also explored the effect of hydrodynamic forces on the offshore pipeline due to wave's loading [100-102]. However, only the static loadings are considered in this paper, and the dynamic loadings are not discussed due to limitation of the size of the paper.

\subsubsection{Buckling of an Initially Perfect Pipe}

Kyriakides and Corona [99] discussed the collapse of an initially perfect pipeline under external hydrostatic pressure. The external pressure is countered by the internal pressure during operation. While, during installation or depressurisation of the pipeline, the pipeline is kept empty, and the internal pressure is zero. Thus, it is crucial to estimate the collapse pressure or critical external pressure. The collapse of the pipeline can be elastic or plastic.

\section{Elastic Local Buckling}

The collapse pressure for an elastically buckled thin-walled pipeline is given by a classical formula:

$$
p_{c}=\left(\frac{2 E_{s}}{1-v_{s}^{2}}\right)\left(\frac{t}{D_{0}}\right)^{3}
$$

The above expression is an extended version of the formula proposed by Levy [103], and it is capable of predicting the elastic collapse pressure of an offshore pipeline more accurately. 


\section{Plastic Local Buckling}

The plastic local buckling of the pipeline depends on the end condition of the pipeline. Thus, three collapse pressures are obtained for three cases:

Case 1: Free end and circumferentially loaded pipe.

The ends of the pipeline are free, and the displacement of the pipeline is unrestrained. Thus, the collapse pressure is given by;

$$
P_{c 1}=\left(\frac{2 C_{22}}{\left(1+\frac{1}{12 \Omega}\left(\frac{t}{r_{m}}\right)^{2}\right)}\right)\left(\frac{t}{D_{0}}\right)^{3}
$$

where, $C_{22}=\frac{\varepsilon_{t}}{\Omega}=$ an element of stiffness matrix; $\Omega=1-\frac{4 v_{t}^{2}}{\left(1+3 \frac{\varepsilon_{t}}{\varepsilon_{S}}\right)} ; \varepsilon_{T}=$ Tangent modulus; $\varepsilon_{S}=$ Secant modulus; $r_{m}=$ mean radius $=(D-t) / 2$

Case 2: Free end and hydrostatically loaded pipe.

Similar to the previous case, the pipeline displacement is also unrestrained in this case. However, the external pressure is applied both at the end and at the circumference of the pipeline. Thus, the collapse pressure is given as;

$$
P_{c 2}=\left(\frac{2 C_{22}}{\left(1+\frac{1}{12 \Omega}\left(\frac{t}{r_{m}}\right)^{2}\right)}\right)\left(\frac{t}{D_{0}}\right)^{3}
$$

where, $C_{22}=\frac{\varepsilon_{s}}{\frac{1}{4}\left(1+3 \frac{\varepsilon_{s}}{\varepsilon_{t}}\right) \Omega}=$ an element of stiffness matrix; $\Omega=1-\frac{4 v_{s}^{2}}{\left(1+3 \frac{\varepsilon_{s}}{\varepsilon_{t}}\right)}$.

The constitutive constant $\left(\mathrm{C}_{22}\right)$ at the right-hand side of the equation depends on the external pressure subjected to the pipeline. Thus, the $C_{22}$ is determined by iteration method. In every iteration, the external pressure is increase until the assumed external pressure becomes equal to the estimated critical buckling pressure.

Case 3: Fixed end and circumferentially loaded pipe.

In this case, zero axial displacement of the pipeline is allowed, and the axial strain of the pipe is zero. This is the case for a pipeline laid or buried within seabed. Thus, the collapse pressure of the pipeline under external pressure is given by:

$$
P_{c 3}=\left(\frac{2 C_{22}}{\left(1+\frac{1}{12 \Omega}\left(\frac{t}{r_{m}}\right)^{2}\right)}\right)\left(\frac{t}{D_{0}}\right)^{3}
$$

where, $C_{22}=\frac{E_{S}}{\left(1-v_{s}^{2}\right)}=$ an element of the stiffness matrix.

The constitutive constants $\left(C_{22}\right)$ at the right-hand side of the equations (Equations (63)-(65)) depend on the external pressure subjected to the pipeline. Thus, the $C_{22}$ is determined by iteration method. In every iteration, the external pressure is increased until the assumed external pressure becomes equal to the estimated critical buckling pressure.

\subsubsection{Local Buckling of an Initially Dented Pipeline}

The external pressure becomes severe when any dent is created in the pipeline due to any accidents [104]. In case of previously formed dents, localised buckling under external pressure initiates from the dent. The buckling starts propagating until the external pressure falls below the propagation pressure or the buckling reaches any buckle arrestor [105]. The buckle propagation for an accidentally dented pipe under external pressure was 
investigated numerically and experimentally by Gong et al. [104]. The researchers proposed a formula to predict buckle propagation pressure. The formula is given as:

$$
\frac{P_{p}}{\sigma_{0}}=\left[23+13\left(\frac{E \prime}{\sigma_{0}}\right)\left(\frac{t}{D}\right)\right]\left(\frac{t}{D}\right)^{2.4}
$$

The collapse pressure for a dented pipeline is always significantly lower than that of an initially perfect pipeline. The researchers observed that the above formula predicted result with a maximum of $10-12 \%$ error.

The localised buckling initiated by initial imperfection and hydrostatic pressure plays a significant role in the pipeline collapse during lateral or upheaval buckling of a pipeline [17] Various authors studied the effect of ovalisation and pipe diameter-to-thickness ratio on pipe collapse pressure $[17,106-109]$. In Figure 17, $f_{O}$ represents the initial ovality of the pipeline, Pc is the collapse pressure of the pipeline, and Po is the yield pressure. Thus, it is observed from Figure 17 that the normalised collapse pressure decreased with increasing diameter-to-thickness ratio and the initial ovality of the pipeline. Moreover, the analytically predicted collapse pressure of the pipeline is closed to the experimentally obtained collapse pressure value. The effect of initial imperfection is observed to be more prominent for low diameter-to-thickness ratio of pipeline. Again, the behaviour of the pipe-buckling was divided into three categories [107]. For very high diameter-to-thickness ratio (D/t), the pipe buckles elastically, and the post-buckling stage is stable. For pipelines with intermediate $\mathrm{D} / \mathrm{t}$, the pipe yields under the combined effect of buckling and membrane stress. Moreover, for pipelines with low $\mathrm{D} / \mathrm{t}$, the buckle propagation pressure for the initially imperfect pipeline was observed to be significantly lower than the critical buckling pressure. Moreover, the local buckling of the pipeline occurs plastically. The researchers also studied the effect of indentation shape on the pipeline's collapse pressure [108]. They observed that the flat indentation for smaller dent gives higher collapse pressure compared to the knife-edge dent. However, the knife-edge indentation provides higher collapse pressure than the spherical and flat dent for the larger indentation.

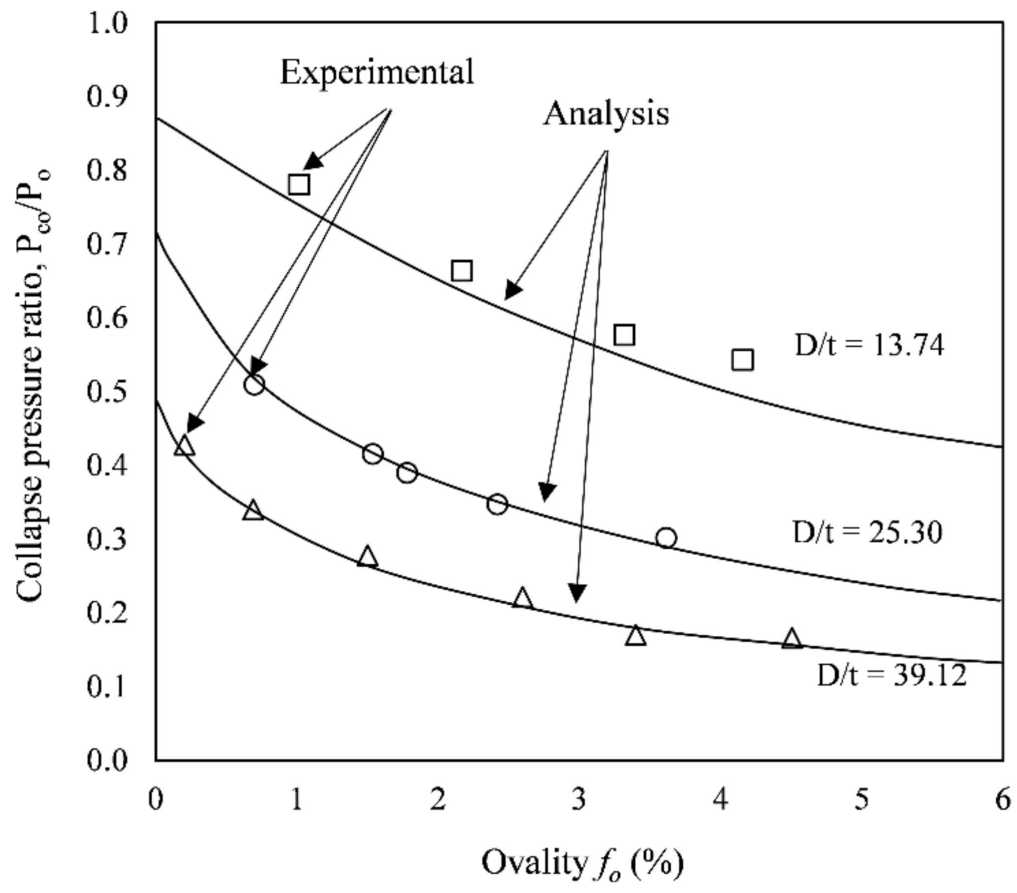

Figure 17. Influence of diameter-to-thickness ratio and initial ovality of the pipeline on the collapse pressure of pipeline under external pressure [108]. 


\subsection{Bending}

During the installation of the pipeline using the S-lay or J-lay method, bending is induced in the pipeline. Moreover, bending is also induced in the pipeline during the global buckling of the pipeline at the operation phase. The bending leads to the formation of plastic hinges as well as ovalisation of the pipeline, which further leads to the collapse of the pipeline [110-112]. Jirsa et al. [110] observed that the moment-curvature relationship was not significantly affected by the ovalisation of the pipeline. Again, Kyriakides and $\mathrm{Ju}$ [111] experimentally explored several pipes' (shells') flexural behaviour and divided their behaviours into three categories based on their diameter-to-thickness ratio. It is observed that the thinner shells $(D / t>40)$ failed by the concentration of ripples even before reaching the natural limit load. While the thicker shells $(D / t<26)$ are found to be failing after reaching the limit load due to ovalisation of the shells. Again, the limit load is clearly defined for the moderately thick shells $(26<\mathrm{D} / \mathrm{t}<40)$. The ripples are observed to be formed almost simultaneously when the limit load is reached due to ovalisation of the shell's cross-section. Followed by this, a catastrophic failure of the pipeline occurs.

Furthermore, the collapse under bending stress is a function of diameter-to-thickness ratio, initial imperfection and axial compressive stress [113-116]. Guo et al. [115] empirically found that the bending strain $\left(\varepsilon_{B}\right)$ is related to the thickness $(t)$ and diameter $(D)$ of the pipeline in the following way,

$$
\varepsilon_{E}=\frac{t}{2 D}
$$

Several authors described the pipe bending from the non-linear beam bending $[113,114]$. They observed that bending stresses are more intensified at the field joint, where the bending stress is critical. Moreover, the pipe material's yield stress in the longitudinal direction significantly influences the pipeline bending capacity. Again, a dented pipeline reaches to collapse pressure more rapidly when compared to an intact pipeline due to stress concentration under bending stress. Thus, Cai et al. [116] proposed an empirical formula to predict the critical bending moment and critical curvature under pure bending moment,

$$
\begin{aligned}
& \frac{M_{c r}}{M_{i}}=1-a_{3}\left(\frac{d_{d}}{t}\right)^{b_{4}}\left(\lambda_{3}\right)^{c_{1}} \\
& \frac{k_{c r}}{k_{i}}=1-\left(a_{4}+\frac{b_{5} t}{d_{d}}\right)\left(\lambda_{3}\right)^{c_{2}}
\end{aligned}
$$

where, $a_{3}=0.017 ; b_{4}=0.696 ; c_{1}=1.48 ; a_{4}=0.192 ; b_{5}=-0.026 ; c_{2}=0.955$.

The predicted result shows a fair comparison with the results obtained from numerical simulations. However, the predicted results slightly underestimate the result obtained from experimental tests. This discrepancy between the prediction and test results is attributed to the difference in material and geometry measurements.

Thus, it is evident from the above discussion that the bending stress is critical during both installation and operational stages. Thus, it is crucial to explore the pipe parameters such as diameter-to-thickness ratio of the pipeline, yield stress of pipeline and their effect on the bending stress of pipeline. Moreover, for initially imperfect pipeline, the shape, length and depth of indentation are considered during the design of a pipeline under bending stress.

\section{Conclusions}

The offshore high pressure-high temperature $(\mathrm{HP} / \mathrm{HT})$ pipelines are often subjected to longitudinal thermal compressive stress. This longitudinal compressive stress further causes the pipeline to buckle. Moreover, the axial compressive force, buckling amplitude, buckling length, and the direction of buckling depends on the factors such as burial condition and properties of seabed soil. Thus, the current paper deals with the uplift and lateral buckling of the surface laid and buried pipeline. It provides insights into the effect of seabed features on deciding the buckling direction, different prediction models to estimate 
the buckling force and buckling resistances, and the effect of various soil parameters on the buckling force, amplitude, and length. The effect of axial resistance of soil on the pipeline buckling and the methods to estimate axial resistance were also discussed as axial soil resistance is crucial in designing an offshore pipeline against buckling. Moreover, the loads subjecting to the pipeline during the installation and operation of the pipelines were also studied.

It is observed that for a surface-laid pipeline, the buckling direction depends on the surface of the seabed. For example, for an uneven seabed with protruded features, the pipelines are prone to uplift buckling under longitudinal compressive stress. While for the even seabed, the lateral buckling or snaking is a more common buckling mode. Again, for a buried pipeline, the most common buckling mode is uplift buckling. It was also observed that the axial resistance of soil decides the likelihood of the buckling occurrence. The major loads coming on a pipeline is external pressure and bending moment during installation and operation. The collapse load of a pipeline under external pressure and bending was observed to depend on the thickness to diameter ratio and elastic modulus of the pipeline. Thus, in this paper, the theoretical and applied background on the phenomena of offshore pipeline's buckling was reviewed, and the basis for further practical cases was presented and summarised.

The previous researches enriched the understanding in the field of pipe buckling. However, many studies were performed in the static analysis of pipeline buckling, but studies addressing the effect of dynamic loading on the pipe buckling are still scarce in the literature. The stability of pipelines during pipeline installation or liquefaction and pipesoil interaction under cyclic wave loading, earthquake force, and flow or working platform induced vibration $[8,9]$ is still open for exploration. The cost-effectiveness and reliability of different stabilisation solutions are also needed to be studied. However, several static aspects of the offshore pipelines are still under investigation. The effect of different load combinations, backfill conditions, installation processes on the buckling behaviour of the pipeline is still open for research.

Author Contributions: Please add Conceptualization, D.S., B.M., J.T.S., T.F.-F., F.T.P. and P.J.R.-S.; methodology, D.S. and B.M.; validation, T.F.-F. and B.M.; formal analysis, D.S. and B.M.; investigation, D.S., B.M., J.T.S., T.F.-F., F.T.P. and P.J.R.-S.; writing-original draft preparation, D.S., B.M. and J.T.S.; writing-review and editing, T.F.-F., F.T.P. and P.J.R.-S.; supervision, F.T.P. and P.J.R.-S.; funding acquisition, F.T.P. and P.J.R.-S. All authors have read and agreed to the published version of the manuscript.

Funding: This research was funded by Fundação para Ciência e Tecnologia, grant/project number/reference POCI-01-0145-FEDER-032170 (Oracle project: Offshore Risk Analysis for Climate Change and Lifetime Extension), funded by the European Fund for Regional Development (FEDER), through COMPETE2020, the Programa Operacional Competitividade e Internacionalização (POCI) and FCT/MCTES through national funds (PIDDAC).

Institutional Review Board Statement: Not applicable.

Informed Consent Statement: Not applicable.

Data Availability Statement: Not applicable because it is a review article.

Conflicts of Interest: The authors declare no conflict of interest.

\section{Glossary}

$a_{1}=5=$ Fitting coefficients in Equation (9)

$a_{2}=0.015 ;$ (constant in Equation (18)

$a_{3}=0.017$; (constant in Equations (68) and (69)

$a_{4}=0.192 ;$ (constant in Equations (68) and (69)

$A=$ Cross-sectional area of pipeline

$A_{1}=$ Calculation parameters relative to soil properties and experimentaly determinate. (Equation 
$A_{2}=$ Modification coefficient of the normal stress on the pipeline and experimentaly determinate. (Equation (61))

$A_{s}=$ Cross-sectional area of soil lifted in vertical slip mechanism. (Equation (23))

$A_{\text {soil }}=$ Area of soil block above the pipe,

$b_{1}=0.15=$ Fitting coefficients in Equation (9)

$b_{2}=2.3$; (constant in Equation (18))

$b_{3}=\left\{\begin{array}{r}0.15 \text { for } \mathrm{w} / \mathrm{D} \leqslant 4 \\ \quad \text { (Equation (47) } \\ 0.2 \text { for } \mathrm{w} / \mathrm{D}>4\end{array}\right.$

$b_{4}=0.696 ;$ (constant in Equations (68) and (69)

$b_{5}=-0.026$; (constant in Equations (68) and (69)

$B=$ Base width of the pipeline

$c_{1}=1.48$; (constant in Equations (68) and (69)

$c_{2}=0.955 ;$ (constant in Equations (68) and (69)

$c=$ Cohesion of soil

$c_{u}=$ Undrained cohesion

$c_{v}=$ Coefficient of consolidation

$C_{22}=$ Element of stiffness matrix. (Equation (63))

$d=$ Maximum drainage path length during consolidation

$d_{d}=$ Depth of dent

$D=$ Pipe Diameter

$D_{0}=(\mathrm{D}-\mathrm{t})=$ Pipe mean diameter

$D_{e}=$ Elasticity matrix

$E^{\prime}=$ Strain hardening modulus. (Equation (66))

$E I=$ Bending stiffness

$E_{p}=$ Modulus of elasticity of pipeline

$E_{s}=$ Modulus of elasticity of soil

$f=$ Yield function. (Equation (7))

$f_{0}=$ The initial ovality of the pipeline,

$f_{1}=$ Lateral resistance of soil

$f_{\mathcal{c}}^{\prime}=$ Factor for the effect of cohesion on anchor behaviour and is a function of embedment ratio, friction angle, and surcharge pressure above the soil. (Equation (52))

$f_{N B A}=$ Factor for obtaining $s_{u, e f f}$ for the ' $\mathrm{kz}$ ' component of $s_{u}$. (Equation (35))

$f_{\gamma}{ }^{\prime}=$ The anchor capacity factor for the basic case of a smooth anchor resting in a soil and is corrected for soil dilatancy, anchor roughness, and initial stress state. (Equation (52))

$F_{b r k}=$ Breakout resistance of pipeline per unit length

$F_{c}=\left(\mathrm{W}_{\mathrm{P}} \_\mathrm{F}_{\mathrm{Z}}\right)=$ Vertical contact force per unit length .

$\Delta F_{H}=$ Horizontal loading rate per unit length

$F_{H}=$ Horizontal loading on pipeline per unit length

$F_{R}=$ Passive soil resistance exerted on the pipe during lateral movement of pipeline per unit length

$F_{Z}=$ Vertical hydrodynamic lift load on Pipeline per unit length

$g=$ Gravitational acceleration

$g_{p}=$ Plastic potential function. (Equation (7))

$h=$ Hardening modulus. (Equation (7))

$H_{m}=$ Maximum buckle amplitude of pipeline.

$\mathrm{H}=$ Buckle amplitude of pipeline.

$I_{p}=$ Second moment of area of cross section of pipeline

$k=$ Incremental soil strength rate

$k_{c r}=$ Critical curvature of an initially dented pipeline

$k_{i}=$ Critical curvature of an intact pipeline;

$k_{o u}$ and $k_{o v}=$ Factors determining the initial stiffness

$k_{u}=$ Limiting value for the axial resistance

$k_{v}=$ Limiting value for the lateral resistance

$k_{t}=$ Rate of strength increase per decade 
$K=$ Coefficient of lateral earth pressure;

$L=$ Buckle length

$L_{0}=$ Buckle length of the imperfection topology

$L_{c r}=$ Critical length of pipeline [32]

$M_{c r}=$ Ultimate bending moment of an initially dented pipeline

$M_{i}=$ Ultimate bending moment of an intact pipeline

$N_{c}=$ Capacity factor, a function of pipe roughness $=10$. (Equation (39))

$N_{c h}=$ Lateral interaction factor dependent on burial depth ratio. (Equation (53))

$N_{p}=$ Bearing capacity factor of the pipeline and function of the pipeline roughness

$\left(9.14<N_{p}<11.94\right)$ [51]. (Equation (40))

$N_{u}=$ Uplift capacity factor;

$N_{u \text { (weightless) }}=$ Uplift capacity factor of soil considering weightless soil. (Equation (32))

$N_{u 0}=$ Uplift capacity for pipe placed at the surface of weightless soil

$N_{u(\text { limit })}=$ Limiting values of $N_{u(\text { weightless) }}$ [61]. (Equation (33))

$P_{h}=$ Hydrostatic pressure

$p_{i}=$ Internal pressure on the pipeline

$P=$ Axial compressive force

$P_{c}=$ Collapse pressure for a pipeline

$P_{c r}=$ Critical axial force

$P_{o}=$ Yield pressure of the pipeline

$P_{p}=$ Buckle propagation pressure

$P_{\text {suction }}=$ Additional suction force per unit length. (Equation (28))

$P_{v}=$ Net uplift force per unit length

$P_{v, \text { total }}=$ Total uplift force per unit length

$q=$ Vertical distributed force on the pipeline

$q_{u}=$ Collapse load of an anchor

$r=$ Outer radius of the pipeline

$r_{m}=$ Mean radius $=(\mathrm{D}-\mathrm{t}) / 2$

$s_{u}=$ Undrained shear strength of soil

$s_{u m}=$ Shear strength of soil at mud-line

$s_{u 0}=$ Original shear strength prior to any rate effect or softening

$s_{u, e f f}=$ Effective undrained shear strength of soil at considered depth

$s_{u, r e f}=$ Undrained shear strength at the soil surface

$S_{t}=$ Sensitivity of clay

$t=$ Pipe wall thickness;

$t_{\text {con }}=$ Time of consolidation;

$t_{\text {plough }}=$ Depth of ploughing

$T_{i}=$ Initial temperature of pipeline

$T_{\text {if }}=$ Temperature of transporting product

$T_{S}=$ Ambient temperature

$\Delta T=$ Temperature difference between transporting fluid and the outside of pipe.

$\Delta u=$ Displacement rate

$u=$ Displacement of pipeline

$U=$ Average degree of consolidation

$V_{H}=$ Horizontal resistance on pipeline per unit length

$V_{H, r e s}=$ Residual horizontal resistance on pipeline

$V_{H, b e r m}=$ Berm resistance during large pipe displacement

$V_{H, \max }=$ Maximum horizontal resistance on pipeline

$V_{t}=$ Total ultimate uplift force of the pipeline

$V_{u}=$ Vertical resistance on pipeline

$V_{u, \max }=$ Vertical bearing capacity on pipeline

$w=$ Pipe embedment depth (distance between the top surface of sea-bed and the top of the pipeline)

$w_{d}=$ Reverse embedment depth or depth of the pipe bottom from the top of the soil-bed

$w_{h}=$ Depth from sea-bed to the bottom of the anchor

$W_{P}=$ Pipe weight per unit length

$W_{S}=$ Total weight of the soil block above the pipe per unit length 
$W_{s}{ }^{\prime}=$ Effective (buoyant) weight of the soil block above the pipe per unit length

$W_{p}{ }^{\prime}=$ Effective (buoyant) weight of the pipe per unit length

$V_{a}=$ Axial resistance of pipes

$V_{a, \max }=$ Maximum axial resistance of pipes

$\Delta z=$ Thickness of soil layer

$Z=$ Considered depth within the seabed

$Z_{w}=$ Water depth

$\alpha=$ Thermal expansion coefficient of Steel

$\alpha_{\mathrm{a}}=$ Activation factor for the clay strength which is between zero and unity.

$\alpha_{d}=$ Dirac's function determined by elastic or plastic state

$\beta_{1}$ and $\beta_{2}=$ Skew parameters in Equations (13) and (14)

$\beta_{3}=$ Curve fitting parameter

$\gamma_{p}=$ Unit weight of steel

$\gamma_{\text {ref }}=$ Reference shear strain rate

$\gamma_{s}=$ Effective unit weight of soil

$\gamma_{s}^{\prime}=$ Submerged unit weight of soil

$\delta=$ Function of normalised berm area $\left(A_{b e r m} / D^{2}\right)$ and berm resistance, $\left(V_{H, b e r m}\right)$ in Equation (18)

$\delta_{a}=$ Axial displacement of pipeline

$\delta_{a, \max }=$ Axial displacement corresponding to $V_{a, \max }$

$\delta_{u, \max }=$ Displacement corresponding to $V_{u, \max }$

$\delta_{u}=$ Vertical displacement

$\delta_{H}=$ Horizontal displacement

$\delta_{H, \max }=$ Horizontal displacement corresponding to $V_{H, \max }$

$\varepsilon_{B}=$ Bending strain of pipeline

$\varepsilon_{T}=$ Tangent modulus

$\varepsilon_{S}=$ Secant modulus

$\varepsilon_{\mathrm{u}}=$ Total strain at ultimate strength of steel

$\xi_{95}=$ Accumulated plastic strain at which $95 \%$ soil strength reduction occurs by remolding

$\theta=$ Friction angle for the pipeline-cover interface

$\lambda=1$; (constant in Equation (18))

$\lambda_{1}, \lambda_{2}, \lambda_{3}$ and $\lambda_{4}=$ Curve fitting parameter in Equation (35)

$\lambda_{3}=$ Normalized dent length in the pipe hoop direction

$\mu=$ Coefficient of friction between the soil and the model pipe

$\mu_{i r}=$ Interface roughness

$\mu_{i t}=$ Interface tensile capacity

$\mu_{L}=$ Lateral friction coefficients

$v_{p}=$ Poisson's ratio of steel

$v_{p h}=$ Horizontal pipeline penetration rate

$v_{p v}=$ Vertical pipeline penetration rate

$v_{s}=$ Poisson's ratio of soil

$\rho_{c}=$ Density of the outer concrete coating of pipeline

$\rho_{\text {if }}=$ Density of transporting material through the pipeline

$\rho_{i}=$ Density of the transporting

$\rho_{p}{ }^{\prime}=$ Submerged Density of steel

$\rho_{S}^{\prime}=$ Submerged Density of soil

$\rho_{w}=$ Density of seawater

$\sigma_{o}=$ API yield stress (0.5\% strain offset). (Equation (66))

$\sigma_{u}=$ Specified minimum tensile strength of steel

$\sigma_{v}{ }^{\prime}=$ Effective stress in the backfill

$\sigma_{y}=$ Specified minimum yield strength of steel

$\tau_{\text {int }}=$ Pipe $/$ soil interface shear strength

$\tau_{u, a v e}=$ Average drained shear strength

$\Phi=$ Friction angle of soil

$\Psi=$ Dilation angle of soil 


\section{References}

1. Fazeres-Ferradosa, T.; Rosa-Santos, P.; Taveira-Pinto, F.; Vanem, E.; Carvalho, H.; Correia, J.A.F.D.O. Editorial: Advanced research on offshore structures and foundation design: Part 1. Proc. Inst. Civ. Eng. Marit. Eng. 2019, 172, 118-123. [CrossRef]

2. Fazeres-Ferradosa, T.; Rosa-Santos, P.; Taveira-Pinto, F.; Pavlou, D.; Gao, F.-P.; Carvalho, H.; Oliveira-Pinto, S. Preface: Advanced Research on Offshore Structures and Foundation Design: Part 2. Proc. Inst. Civ. Eng. Marit. Eng. 2020, 173, 96-99. [CrossRef]

3. Fazeres-Ferradosa, T.; Welzel, M.; Schendel, A.; Baelus, L.; Santos, P.R.; Pinto, F.T. Extended characterization of damage in rubble mound scour protections. Coast. Eng. 2020, 158, 103671. [CrossRef]

4. Taveira-Pinto, F.; Rosa-Santos, P.; Fazeres-Ferradosa, T. Marine renewable energy. Renew. Energy 2020, 150, 1160-1164. [CrossRef]

5. Paiva, P.M.; Junior, J.L.; Calderon, E.N.; Juliano, M.M.F.; Molisani, M.M. Decommissioning of subsea oil and gas production pipelines: Hydrodynamic modeling for preliminary assessment of sediment resuspension and burial onto benthic organisms. $J$. Integr. Coast. Zone Manag. 2020, 20, 161-168. [CrossRef]

6. Pavlou, D.G.; Li, Y. Seabed Dynamic Response of Offshore Wind Turbine Foundation under Vertical Harmonic Loading: An Analytic Solution. Math. Probl. Eng. 2018, 2018, 1-9. [CrossRef]

7. Ghodoosipour, B.; Stolle, J.; Nistor, I.; Mohammadian, A.; Goseberg, N. Experimental study on extreme hydrodynamic loading on pipelines. Part 1: Flow hydrodynamics. J. Mar. Sci. Eng. 2019, 7, 251. [CrossRef]

8. Pavlou, D.G. Dynamic response of a multi-layered FRP cylindrical shell under unsteady loading conditions. Eng. Struct. 2016, 112, 256-264. [CrossRef]

9. Pavlou, D.G.; Ong, M.C. Damping Effect on the Wave Propagation in Carbon Steel Pipelines Under Fluid Hammer Conditions. J. Offshore Mech. Arct. Eng. 2017, 139, 041702. [CrossRef]

10. Pavlou, D.G. Flow-Riser Interaction in Deep-Sea Mining: An Analytic Approach for Multi-Layered FRP Risers. In Proceedings of the ASME 2018 37th International Conference on Ocean, Offshore and Arctic Engineering, Madrid, Spain, 17-22 June 2018.

11. Li, F.Z.; Dwivedi, A.; Low, Y.M.; Hong, J.-H.; Chiew, Y.-M. Experimental Investigation on Scour under a Vibrating Catenary Riser. J. Eng. Mech. 2013, 139, 868-878. [CrossRef]

12. Zhang, X.; Duan, M. Prediction of the upheaval buckling critical force for imperfect submarine pipelines. Ocean Eng. 2015, 109, 330-343. [CrossRef]

13. Mondal, B.C.; Dhar, A.S. Upheaval buckling of surface-laid offshore pipeline. Appl. Ocean Res. 2017, 66, 146-155. [CrossRef]

14. Xu, L.; Lin, M. Numerical study on critical axial forces of upheaval buckling for initially stressed submarine pipelines on uneven seabed. Ocean Eng. 2017, 145, 344-358. [CrossRef]

15. Liang, Z.; Lu, X.; Zhang, J. Thermal vertical buckling of surface-laid submarine pipelines on a sunken seabed. Ocean Eng. 2019, 173, 331-344. [CrossRef]

16. Taylor, N.; Gan, A.B. Submarine pipeline buckling-Imperfection studies. Thin-Walled Struct. 1986, 4, 295-323. [CrossRef]

17. Karampour, H.; Albermani, F.; Gross, J. On lateral and upheaval buckling of subsea pipelines. Eng. Struct. 2013, 52, 317-330. [CrossRef]

18. Liu, R.; Yan, S.; Wu, X. Model Test Studies on Soil Restraint to Pipeline Buried in Bohai Soft Clay. J. Pipeline Syst. Eng. Pract. 2013, 4, 49-56. [CrossRef]

19. Shi, R.; Wang, L.; Guo, Z.; Yuan, F. Upheaval buckling of a pipeline with prop imperfection on a plastic soft seabed. Thin-Walled Struct. 2013, 65, 1-6. [CrossRef]

20. Zeng, X.; Duan, M.; Che, X. Critical upheaval buckling forces of imperfect pipelines. Appl. Ocean Res. 2014, 45, 33-39. [CrossRef]

21. Chen, R.P.; Zhu, B.; Ni, W.J. Uplift tests on full-scale pipe segment in lumpy soft clay backfill. Can. Geotech. J. 2016, 53, 578-588. [CrossRef]

22. Winterkorn, H.F.; Fang, H.Y. (Eds.) Foundation Engineering Handbook; Van Nostrand Reinhold Co.: New York, NY, USA, 1975; pp. 166-179.

23. Hansen, J.B. A Revised and Extended Formula for Bearing Capacity; Bulletin No. 28; Geoteknisk Institute: Copenhagen, Denmark, 1970.

24. Schotman, G.J.M.; Stork, F.G. Pipe-Soil Interaction: A Model for Laterally Loaded Pipelines in Clay. In Proceedings of the Offshore Technology Conference, Houston, TX, USA, 27-30 April 1987.

25. Verley, R.L.P.; Sotberg, T. A Soil Resistance Model for Pipelines Placed on Sandy Soils. J. Offshore Mech. Arct. Eng. 1994, 116, 145-153. [CrossRef]

26. Merifield, R.; White, D.J.; Randolph, M.F. The ultimate undrained resistance of partially embedded pipelines. Géotechnique 2008, 58, 461-470. [CrossRef]

27. Wang, Z.; Tang, Y.; Feng, H.; Zhao, Z.; Liu, H. Model test for lateral soil resistance of partially embedded subsea pipelines on sand during large-amplitude lateral movement. J. Coast. Res. 2017, 33, 607-618.

28. Chatterjee, S.Y.; White, D.J.; Randolph, M.D. Numerical simulations of pipe-soil interaction during large lateral movements on clay. Géotechnique 2012, 62, 693-705. [CrossRef]

29. Merifield, R.S.; White, D.J.; Randolph, M.F. Effect of Surface Heave on Response of Partially Embedded Pipelines on Clay. J. Geotech. Geoenvironmental Eng. 2009, 135, 819-829. [CrossRef]

30. White, D.J.; Cheuk, C.Y. Modelling the soil resistance on seabed pipelines during large cycles of lateral movement. Mar. Struct. 2008, 21, 59-79. [CrossRef] 
31. Liu, R.; Liu, W.B.; Wu, X.L.; Yan, S.W. Global lateral buckling analysis of idealized subsea pipelines. J. Cent. South Univ. 2014, 21, 416-427. [CrossRef]

32. Zhu, J.; Attard, M.M.; Kellermann, D.C. In-plane nonlinear localised lateral buckling of straight pipelines. Eng. Struct. 2015, 103, 37-52. [CrossRef]

33. $\mathrm{Hu}, \mathrm{Y}$; Randolph, M.F. A practical numerical approach for large deformation problems in soil. Int. J. Numer. Anal. Methods Geomech. 1998, 22, 327-350. [CrossRef]

34. Bruton, D.; White, D.; Cheuk, C.; Bolton, M.; Carr, M. Pipe/Soil Interaction Behavior During Lateral Buckling, Including Large-Amplitude Cyclic Displacement Tests by the Safebuck JIP. In Proceedings of the Offshore Technology Conference, Houston, TX, USA, 1-4 May 2006.

35. Cheuk, C.Y.; White, D.J.; Bolton, M.D. Large-scale modelling of soil-pipe interaction during large amplitude cyclic movements of partially embedded pipelines. Can. Geotech. J. 2007, 44, 977-996. [CrossRef]

36. Konuk, I.; Yu, S. Continuum FE modeling of lateral buckling: Study of soil effects. In Proceedings of the International Conference on Offshore Mechanics and Arctic Engineering, San Diego, CA, USA, 10-15 June 2007; pp. 347-354.

37. Cardoso, C.O.; Silveira, R. Pipe-Soil Interaction Behavior for Pipelines Under Large Displacements on Clay Soils—A Model for Lateral Residual Friction Factor. In Proceedings of the Offshore Technology Conference, Houston, TX, USA, 3-6 May 2010.

38. Wang, D.; White, D.J.; Randolph, M.F. Large-deformation finite element analysis of pipe penetration and large-amplitude lateral displacement. Can. Geotech. J. 2010, 47, 842-856. [CrossRef]

39. Rismanchian, A.; White, D.J.; Randolph, M.F.; Martin, C.M. Shear strength of soil berm during lateral buckling of subsea pipelines. Appl. Ocean Res. 2019, 90, 101864. [CrossRef]

40. Dingle, H.R.C.; White, D.J.; Gaudin, C. Mechanisms of pipe embedment and lateral breakout on soft clay. Can. Geotech. J. 2008, 45, 636-652. [CrossRef]

41. White, D.J.; Gaudin, C.; Boylan, N.; Zhou, H. Interpretation of T-bar penetrometer tests at shallow embedment and in very soft soils. Can. Geotech. J. 2010, 47, 218-229. [CrossRef]

42. Ravet, F.; Zou, L.; Bao, X.; Chen, L.; Huang, R.F.; Khoo, H.A. Detection of buckling in steel pipeline and column by the distributed Brillouin sensor. Opt. Fiber Technol. 2006, 12, 305-311. [CrossRef]

43. Ansari, F. Practical Implementation of Optical Fiber Sensors in Civil Structural Health Monitoring. J. Intell. Mater. Syst. Struct. 2007, 18, 879-889. [CrossRef]

44. Bao, X. Optical Fiber Sensors Based on Brillouin Scattering. Opt. Photon News 2009, 20, 40-45. [CrossRef]

45. Glisic, B.; Yao, Y. Fiber optic method for health assessment of pipelines subjected to earthquake-induced ground movement. Struct. Heal. Monit. 2012, 11, 696-711. [CrossRef]

46. Feng, X.; Wu, W.; Li, X.; Zhang, X.; Zhou, J. Experimental investigations on detecting lateral buckling for subsea pipelines with distributed fiber optic sensors. Smart Struct. Syst. 2015, 15, 245-258. [CrossRef]

47. Vanem, E.; Fazeres-Ferradosa, T.; Rosa-Santos, P.; Taveira-Pinto, F. Statistical description and modelling of extreme ocean wave conditions. Proc. Inst. Civ. Eng. Marit. Eng. 2019, 172, 124-132. [CrossRef]

48. Wu, J.; Kouretzis, G.P.; Suwal, L.P.; Ansari, Y.; Sloan, S.W. Shallow and deep failure mechanisms during uplift and lateral dragging of buried pipes in sand. Can. Geotech. J. 2020, 57, 1472-1483. [CrossRef]

49. Seth, D.; Manna, B.; Shahu, J.T.; Fazeres-Ferradosa, T.; Taveira-Pinto, F.; Rosa-Santos, P.; Pinto, F.V.T. Offshore pipeline buried in Indian coastal clay: Buckling behaviour analysis. Ships Offshore Struct. 2021, 1-16. [CrossRef]

50. Schaminee, P.E.L.; Zorn, N.F.; Schotman, G.J.M. Soil Response for Pipeline Upheaval Buckling Analyses: Full-Scale Laboratory Tests and Modelling. In Proceedings of the Offshore Technology Conference, Houston, TX, USA, 7-10 May 1990.

51. Bransby, M.F.; Newson, T.A.; Brunning, P. Centrifuge modelling of the upheaval capacity of pipelines in liquefied clay. In Proceedings of the Twelfth International Offshore and Polar Engineering Conference, Kitakyushu, Japan, 25-31 May 2001.

52. Newson, T.A.; Deljoui, P. Finite Element Modelling of Upheaval Buckling of Buried offshore Pipelines in Clayey Soils. In Soil and Rock Behavior and Modeling, Proceedings of the GeoShanghai International Conference, Shanghai, China, 6-8 June 2006; ASCE: Reston, VA, USA, 2006.

53. Hodder, M.S.; Cassidy, M.J. A plasticity model for predicting the vertical and lateral behaviour of pipelines in clay soils. Géotechnique 2010, 60, 247-263. [CrossRef]

54. Martin, C.; White, D. Limit analysis of the undrained bearing capacity of offshore pipelines. Géotechnique 2012, 62, 847-863. [CrossRef]

55. Chen, Z.; Yang, J.; Wang, Z. Numerical study on upheaval buckling for surface laid subsea pipelines with topographic step imperfection. Appl. Ocean Res. 2020, 101, 102232. [CrossRef]

56. Maitra, S.; Chatterjee, S.; Choudhury, D. Generalized framework to predict undrained uplift capacity of buried offshore pipe-lines. Can. Geotech. J. 2016, 53, 1841-1852. [CrossRef]

57. Brennan, A.J.; Ghahremani, M.; Brown, M.J. Strength reduction for upheaval buckling of buried pipes in blocky clay backfill. Ocean Eng. 2017, 130, 210-217. [CrossRef]

58. Kumar, P.; Seth, D.; Manna, B.; Shahu, J.T. Lateral and Uplift Capacity of Pipeline Buried in Seabed of Homogeneous Clay. J. Pipeline Syst. Eng. Pract. 2021, 12, 04021020. [CrossRef]

59. Seth, D.; Manna, B.; Kumar, P.; Shahu, J.T.; Fazeres-Ferradosa, T.; Taveira-Pinto, F.; Rosa-Santos, P.; Carvalho, H. Uplift and lateral buckling failure mechanisms of offshore pipes buried in normally consolidated clay. Eng. Fail. Anal. 2021, 121, 105161. [CrossRef] 
60. Da Costa, A.M.; de Oliveira Cardoso, C.; dos Santos Amaral, C.; Andueza, A. Soil-structure interaction of heated pipeline buried in soft clay. In Proceedings of the International Pipeline Conference, Calgary, AB, Canada, 29 September-3 October 2002; pp. 457-466.

61. Randolph, M.F.; Houlsby, G.T. The limiting pressure on a circular pile loaded laterally in cohesive soil. Geotechnique 1984, 34, 613-623. [CrossRef]

62. Ansari, Y.; Kouretzis, G.; Sloan, S.W. Development of a prototype for modelling soil-pipe interaction and its application for predicting uplift resistance to buried pipe movements in sand. Can. Geotech. J. 2018, 55, 1451-1474. [CrossRef]

63. Trifonov, O.V.; Cherniy, V.P. Mathematical models of pipeline-soil interaction. Adv. Environ. Res. 2017, 58, 65-103.

64. Veritas, D.N. Global Buckling of Submarine Pipelines, Structural Design due to High Temperature/High Pressure; RP-F110; DNV: Oslo, Norway, 2007.

65. Rowe, R.K.; Davis, E.H. The behaviour of anchor plates in sand. Geotechnique 1982, 32, 25-41. [CrossRef]

66. Liu, R.; Basu, P.; Xiong, H. Laboratory tests and thermal buckling analysis for pipes buried in Bohai soft clay. Mar. Struct. 2015, 43, 44-60. [CrossRef]

67. Gao, X.-F.; Liu, R.; Yan, S.-W. Model test based soil spring model and application in pipeline thermal buckling analysis. China Ocean Eng. 2011, 25, 507. [CrossRef]

68. Peng, L.C. Stress analysis methods for underground pipelines. Pipe Line Ind. 1978, 47, 65-74.

69. Wang, Z.; van der Heijden, G.H.M.; Tang, Y. Localised upheaval buckling of buried subsea pipelines. Mar. Struct. 2018, 60, 165-185. [CrossRef]

70. Merifield, R.S.; Sloan, S.W.; Yu, H.S. Stability of plate anchors in undrained clay. Géotechnique 2001, 51, 141-153. [CrossRef]

71. Charlton, T.S.; Rouainia, M. Probabilistic analysis of the uplift resistance of buried pipelines in clay. Ocean Eng. 2019, $186,105891$. [CrossRef]

72. Trautmann, C.H. Behavior of Pipe in Dry Sand under Lateral and Uplift Loading. Ph.D. Thesis, Cornell University, Ithaca, NY, USA, 1983.

73. Bransby, M.F.; Newson, T.A.; Brunning, P.; Davies, M.C. Numerical and centrifuge modeling of the upheaval resistance of buried pipelines. In Proceedings of the OMAE Pipeline Symposium, Rio de Janeiro, Brazil, 3-8 June 2001.

74. Cathie, D.N.; Jaeck, C.; Ballard, J.C.; Wintgens, J.F. Pipeline geotechnics-state-of-the-art. In Proceedings of the 1st International Symposium on Frontiers in Offshore Geotechnics, Perth, Australia, 19-21 September 2005; pp. 95-114.

75. Clukey, E.C.; Haustermans, L.; Dyvik, R. Model tests to simulate riser-soil interaction in touchdown point region. In Proceedings of the 1st International Symposium on Frontiers in Offshore Geotechnics, Perth, Australia, 19-21 September 2005; pp. 651-658.

76. Vanden Berghe, J.F.; Cathie, D.; Ballard, J.C. Pipeline uplift mechanisms using finite element analysis. In Proceedings of the 16th International Conference on Soil Mechanics and Geotechnical Engineering, Osaka, Japan, 12-16 September 2005; pp. 1801-1804.

77. Robert, D.J.; Thusyanthan, N.I. Numerical and Experimental Study of Uplift Mobilization of Buried Pipelines in Sands. J. Pipeline Syst. Eng. Pract. 2015, 6, 04014009. [CrossRef]

78. Roy, K.; Hawlader, B.; Kenny, S.; Moore, I. Uplift Failure Mechanisms of Pipes Buried in Dense Sand. Int. J. Géoméch. 2018, 18, 04018087. [CrossRef]

79. Roy, K.; Hawlader, B.; Kenny, S.; Moore, I. Upward Pipe-Soil Interaction for Shallowly Buried Pipelines in Dense Sand. J. Geotech Geoenvironmental Eng. 2018, 144, 04018078. [CrossRef]

80. Pedersen, P.T.; Jensen, J.J. Upheaval creep of buried heated pipelines with initial imperfections. Mar. Struct. 1988, 1, 11-22. [CrossRef]

81. Cheuk, C.Y.; White, D.J.; Bolton, M.D. Deformation mechanisms during uplift of buried pipes in sand. In Proceedings of the 16th International Conference on Soil Mechanics and Geotechnical Engineering, Osaka, Japan, 12-16 September 2005; pp. 1685-1688.

82. Thusyanthan, N.I.; Mesmar, S.; Wang, J.; Haigh, S.K. Uplift resistance of buried pipelines and DNV-RP-F110 guidelines. In Proceedings of the Offshore Pipeline and Technology Conference, Houston, TX, USA, 3-6 May 2010; pp. 24-25.

83. Dickin, E.A. Uplift Resistance of Buried Pipelines in Sand. Soils Found. 1994, 34, 41-48. [CrossRef]

84. Chin, E.L.; Craig, W.H.; Cruickshank, M. Uplift resistance of pipelines buried in cohesionless soil. In Physical Modelling in Geotechnics, Proceedings of the 6th International Conference on Physical Modelling in Geotechnics, Hong Kong, China, 4-6 August 2006; Taylor \& Francis: London, UK, 2006; Volume 1, pp. 723-728.

85. Cheuk, C.Y.; White, D.J.; Bolton, M.D. Uplift mechanisms of pipes buried in sand. J. Geotech. Geoenviron. Eng. 2008, 134, 154-163. [CrossRef]

86. White, D.J.; Take, W.A.; Bolton, M.D.; Munachen, S.E. A deformation measurement system for geotechnical testing based on digital imaging, close-range photogrammetry, and PIV image analysis. In Proceedings of the International Conference on Soil Mechanics and Geotechnical Engineering, Istanbul, Turkey, 27-31 August 2001; pp. 539-542.

87. Cheuk, C.Y.; Take, W.A.; Bolton, M.D.; Oliveira, J.R.M.S. Soil restraint on buckling oil and gas pipelines buried in lumpy clay fill. Eng. Struct. 2007, 29, 973-982. [CrossRef]

88. Phillips, R.; Nobahar, A.; Zhou, J. Trench Effects on Pipe-Soil Interaction. In Proceedings of the International Pipeline Conference, Calgary, AB, Canada, 4-8 October 2004; pp. 321-327.

89. Hansen, J.B. The Ultimate Resistance of Rigid Piles against Transversal Forces; Bulletin No. 12; Geoteknisk Institute: Copenhagen, Denmark, 1961. 
90. Chaloulos, Y.K.; Bouckovalas, G.D.; Zervos, S.D.; Zampas, A.L. Lateral soil-pipeline interaction in sand backfill: Effect of trench dimensions. Comput. Geotech. 2015, 69, 442-451. [CrossRef]

91. Chaloulos, Y.K.; Bouckovalas, G.D.; Karamitros, D.K. Trench effects on lateral p-y relations for pipelines embedded in stiff soils and rocks. Comput. Geotech. 2017, 83, 52-63. [CrossRef]

92. Anand, S.; Aganwal, S.L. Field and laboratory studies for evaluating submarine pipeline frictional resistance. In Proceedings of the Offshore Technology Conference, Houston, TX, USA, 5-8 May 1980.

93. Popescu, R.; Phillips, R.; Konuk, I.; Guo, P.; Nobahar, A. Pipe-soil interaction: Large scale tests and numerical modelling. In Proceedings of the International Conference on Physical Modelling in Geotechnics, New Foundland, NL, Canada, 10-12 July 2002; pp. 917-922.

94. Murff, J.D. The Geotechnical Centrifuge in Offshore Engineering. In Proceedings of the Offshore Technology Conference, Houston, TX, USA, 6-9 May 1996.

95. Hobbs, R.E. In-Service Buckling of Heated Pipelines. J. Transp. Eng. 1984, 110, 175-189. [CrossRef]

96. Hobbs, R.E.; Liang, F. Thermal buckling of pipelines close to restraints. In Proceedings of the 8th International Conference on Offshore Mechanics \& Arctic Engineering, Hague, The Netherlands, 19-23 March 1989.

97. Maltby, T.C.; Calladine, C.R. An investigation into upheaval buckling of buried pipelines-II. Theory and analysis of experi-mental observations. Int. J. Mech. Sci. 1995, 37, 965-983. [CrossRef]

98. American Lifeline Alliance (ALA). Guidelines for the Design of Buried Pipe. 2001. Available online: http://www. americanlifelinesalliance.com/pdf/Update061305.pdf (accessed on 28 January 2021).

99. Kyriakides, S.; Corona, E. Mechanics of Offshore Pipelines: Volume 1 Buckling and Collapse; Elsevier: Amsterdam, The Netherlands, 2007.

100. Bryndum, M.B.; Jacobsen, V.B.; Brand, L.P. Hydrodynamic forces from wave and current loads on marine pipeline. In Proceedings of the Offshore Technology Conference, Houston, TX, USA, 2-5 May 1983.

101. Liang, Z.; Jeng, D.-S.; Liu, J. Combined wave-current induced seabed liquefaction around buried pipelines: Design of a trench layer. Ocean Eng. 2020, 212, 107764. [CrossRef]

102. Tang, G.; Cheng, L.; Lu, L.; Teng, Y.; Zhao, M.; An, H. Effect of oscillatory boundary layer on hydrodynamic forces on pipelines. Coast. Eng. 2018, 140, 114-123. [CrossRef]

103. Levy, M. Memoire sur un nouveau cas integrable du probleme de l'elastique et l'une des ses applications. Journal de Mathématiques. Pures Appl. 1884, 10, 5-42.

104. Gong, S.; Sun, B.; Bao, S.; Bai, Y. Buckle propagation of offshore pipelines under external pressure. Mar. Struct. 2012, 29, 115-130. [CrossRef]

105. Kyriakides, S.; Park, T.-D.; Netto, T.A. On the design of integral buckle arrestors for offshore pipelines. Appl. Ocean Res. 1998, 20, 95-104. [CrossRef]

106. Kennedy, C.R.; Venard, J.T. Collapse of Tubes by External Pressure; Technical Report No. ORNL-TM-166; Oak Ridge National Lab.: Oak Ridge, TN, USA, 1962.

107. Dyau, J.Y.; Kyriakides, S. On the propagation pressure of long cylindrical shells under external pressure. Int. J. Mech. Sci. 1993, 35, 675-713. [CrossRef]

108. Ramasamy, R.; Ya, T.T. Nonlinear finite element analysis of collapse and post-collapse behaviour in dented submarine pipelines. Appl. Ocean Res. 2014, 46, 116-123. [CrossRef]

109. Yan, S.-T.; Shen, X.-L.; Jin, Z.-J.; Ye, H. On elastic-plastic collapse of subsea pipelines under external hydrostatic pressure and denting force. Appl. Ocean Res. 2016, 58, 305-321. [CrossRef]

110. Jirsa, J.O.; Lee, F.H.; Wilhoit, J.C.; Merwin, J.E. Ovaling Of Pipelines Under Pure Bending. In Proceedings of the Offshore Technology Conference, Houston, TX, USA, 1-3 May 1972.

111. Kyriakides, S.; Ju, G.T. Bifurcation and localization instabilities in cylindrical shells under bending-I. Experiments. Int. J. Solids Struct. 1992, 29, 1117-1142. [CrossRef]

112. Elchalakani, M.; Zhao, X.L.; Grzebieta, R.H. Plastic mechanism analysis of circular tubes under pure bending. Int. J. Mech. Sci. 2002, 44, 1117-1143. [CrossRef]

113. Powers, J.T.; Finn, L.D. Stress Analysis During of Offshore Pipelines Installation. In Proceedings of the Offshore Technology Conference, Houston, TX, USA, 17-20 May 1969.

114. Bryndum, M.B.; Colquhoun, R.S.; Verwey, A.B. Dynamic Lay Stresses for Pipelines. In Proceedings of the Offshore Technology Conference, Houston, TX, USA, 3-6 May 1982.

115. Guo, B.; Song, S.; Ghalambor, A.; Lin, T.R. Offshore Pipelines: Design, Installation, and Maintenance; Gulf Professional Publishing: Waltham, MA, USA; Oxford, UK, 2013.

116. Cai, J.; Jiang, X.; Lodewijks, G.; Pei, Z.; Wu, W. Residual ultimate strength of seamless metallic pipelines under a bending moment-a numerical investigation. Ocean Eng. 2018, 164, 148-159. [CrossRef] 